\title{
III.
}

(Aus dem hygienischen Institut der kgl. Universität Messina.)

\section{Ueber die Wirkung der löslichen Produkte der Blastomyceten in bezug auf die Aetiologie der malignen Geschwiilste.}

Von

\author{
Prof. Franceseo Sanfelice.
}

(Hierzu TafeI I und II.)

I.

Im Bestreben, die Bedeutung der pathogenen Blastomyceten als Erreger bösartiger Geschwülste zu entkräften, riefen mehrere Autoren als Hauptzeugen ihrer Einwendangen die spärliche Anzahl positiver Ergebnisse der Reinkulturenimpfung auf Hunde vor die Schranken. Die Behauptung, dass die zum Vorschein gekommenen Tumoren ihr Entstehen dem injizierten Parasiten verdanken, sei daher nicht auf endgiltige Tatsachen gestützt, sonderu man habe es lediglich als Werk des Zufalls zu betrachten, wäbrend den Pilzen keine Beteiligung zustehe.

Nun beträgt der von mir bei Hunden erzielte Prozentsatz 10,3, während Casper nur 4,7, Johne 5,8 notierte; immerhin ein erklecklicher Vorteil zu meinen Gunsten, der schon an sich die Berechtigung des Einwands erschüttert. Mein Hauptbestreben war ja darauf gerichtet, durch Impfen den Prozentsatz positiver Resultate erheblich zu steigern, gerade in der Absicht, mit derartigen ebenso bequemen als oberflächlichen Anfechtungen aufzuräumen.

Das früher angewandte Verfahren bestand darin, dass ich etwas mit sterilisiertem Wasser verdünnten Kulturbelag injizierte. Die in vitro gebildeten Produkte kamen somit nicht in Betracht und zwar aus dem Grunde, weil ich damals noch weit davon entfernt war, diesen Produkten bei der pathogenen Wirkung, welche die Sprosshefen auf den tierischen Organismus ausüben können, irgend welche Bedeutung beizumessen. In 
dieser Meinung hatte mich eine 1896 veröffentlichte ${ }^{1}$ ) Serie von Versuchen bestärkt, wo die von Saccharomyces neoformans in einer, aus 1 Teil Glukose and 1 Teil Pepton in 100 Teilen Wasser bestehenden Flüssigkeit gebildeten löslichen Produkte in Frage kamen. Selbst in beträchtlicher Quantität in das subkutane Bindegewebe von Meerschweinchen geimpft, brachten sie nicht nur keinerlei Veränderung hervor, sondern waren auch unvermögend, Tiere derselben Spezies, die mit etwas virulenter Kultur des gleichen Pilzes infiziert waren, vor dem Untergang zu schützen. Vielleicht eignete sich die Zusammensetzung der Flüssigkeit nicht zur Bildung auf den·Organismus wirksamer löslicher Produkte.

Vor 3 Jahren mit endotrachealen Impfiversuchen an Meerschweinchen und Kaninchen beschäftigt, machte ich folgende Beobachtung: Auf Injektion der Parasiten allein erfolgte eine ganz beträchtliche Vermehrung derselben, während das Gewebe nur spärlich reagierte; kamen dagegen zugleich mit dem Pilze auch seine auf festem Nährsubstrat gebildeten Produkte zur Verwendung, so fiel die Vermehrung des Parasiten dürftig aus und fand dafür starkes Wuchern der Zellelemente statt. Andererseits erbrachte Impfen in die Trachea mit dem Hefepilz allein bei Kaninchen keinen positiven Erfolg, während er, zugleich mit seinen löslichen Produkten injiziert, unabweislich zum Tode der Tiere und zu einem Sektionsbefund mit ansehnlichen Lungenveränderungen führte.

Aus dieser - erst kürzlich im Druck erschienenen ${ }^{2}$ ) - ersten $\mathbf{A b}$ teilung einschlägiger Experimente geht mit überzeugender Klarheit hervor, welche hervorragende Rolle die löslichen Produkte in der Genesis der Lungenveränderungen spielen.

Der Erfolg ermatigte mich, unverweilt die Wirkung eingehend zu studieren, welche die Parasiten vereint mit ihren löslichen Produkten, sowie letztere allein, auf Hunde und Katzen auszuüben fähig sind, und dabei nahm ich, mit den bezüglichen Experimenten Hand in Hand, eine ausgiebige Versuchsreihe mit Kaninchen und Heerschweinchen vor. Es scheint mir nämlich, als befinde v. Hansemann sich im Irrtum, wenn er letztgenannte Tiere als zu derartigen Untersuchungen untauglich erklärt, einzig und allein, weil bis zur Stunde Niemand dem spontanen Auftreten des Krebses im betreffenden Tierkörper beigewohnt hat. Als ob man bis hente schon einmal den Milzbrand sich am Meerschweinchen spontan entwickeln gesehen hätte, und doch zählt gerade dieses Tier zu den für Milzbrandinfektion empfänglichsten Arten.

1) Sanfelice, Ueber die Immunität gegen Blastomyceten. Zentralbl. f. Bakteriol. 1896.

2) Sanfelice, Ueber die pathogene Wirkung der in die Trachea geimpften Blastomyceten. Zentralbl. f. Bakteriol. 1906. 
168 F. Sanfelice, Ueber die Wirkung der löslichen Produkte der Blastomyceten usw.

Zur Bereicherung des Impfmaterials ward meiner schon bestehenden Sammlung pathogener Blastomyceten noch ein Pilz einverleibt, den ich aus der Geschwulst einer damit behafteten grossen dänischen Dogge isolierte. Am Penis des Hundes, der mir anfangs letzten Jahres gebracht wurde, befand sich ein dickes, blumenkohlähnliches Gewächs. Der grössere Teil der Geschwulst sass auf der Parietalmukosa der Vorhaut, der kleinere knotenförmige direkt auf dem Penis selbst. Es handelte sich um ein Sarkom, wie ich sie ganz ähnlich schon bei anderen Hunden experimentell untersucht und in den früheren Arbeiten beschrieben habe. Nachdem das Tier getötet, wurden unverzüglich einige haselnussgrosse Stückchen der Geschwulst einem Hund, einer Katze und einem Kaninchen, nach Inzision der Cutis, in das Unterhautbindegewebe des Rückens eingebracht und die Wunde zugenäht. Der Hund starb nach 1 Monat, bei Untersuchung der Impfstelle zeigte es sich, dass das. eingeführte Tumorstück resorbiert war. Ebensowenig $\mathrm{kam}$ an derselben Stelle und in den Organen der nach 11/2 Monaten gestorbenen Katze zum Vorschein. Nach dem schon am 5. Tage eingetretenen Tode des Kaninchens fand sich das eingefübrte Stück des Tumors reichlich von Eiter umgeben an der Impfstelle vor. An den Organen liessen sich keine Veränderungen wahrnehmen. Der mikroskopisch untersuchte Eiter wies ziemlich viele Hefepilze auf. Nun wurde zur Aussaat des Eiters vorgegangen, indem man an der Oberfläche ausgiebiger Kartoffelschnitte Strich-, und in Agar, unter Mostzusatz, Plattenkulturen anlegte. Wenn auch mit nicht geringer Mübe, gelang es sowohl auf den Kartoffeln, als auf den Agarplatten, mitten unter zahlreichen Kolonien anderer Mikroorganismen, diejenigen des Blastomyceten $\mathrm{zu}$ isolieren. Morphologisch wie hinsichtlich der kulturgemässen Eigenschaften war der Hefepilz den übrigen pathogenen Arten meiner Sammlung vollkommen ähnlich.

Die Erwägung der Tatsachen, dass die Geschwulst des Hundes nicht ulzeriert war und andererseits durch Uebertragung der isolierten Hefe mittels subkutaner Impfung in der Nähe des Penis bei einem anderen Hunde eine in der Struktur dem Krankheitsherd, wo er isoliert warde, durchaus ähnliche Geschwulst auftrat, zwingt zu der Annahme, dass sein Entstehen keineswegs dem Zufall zuzuschreiben sei.

Ich bezeichnete diesen Pilz zur Unterscherdung als Saccharomyces canis II.

Wird die Hefe im Röhrchen auf Kartoffel ausgesät und jenes bloss mit Baumwollwatte zugepfropft, so bleiben die Pilzchen lange Zeit am Leben, da das Substrat seiner Feuchtigkeit verlustig geht, bevor die Parasiten sämtlichen Nahrungsstoff verzehrt haben. Ist letzteres einmal eingetrocknet, so dauern die Sprosshefen jahrelang. aus und bewahren ihre pathogene Wirkungskraft unversehrt. Schliesst man dagegen nach erfolgter 
Aussaat das Röhrchen mit dem Näbrboden über der Flamme und lässt das Keimen im Wärmeschrank bei $37^{\circ} \mathrm{C}$. vor sich gehen, so stirbt die Kultur schon nach 20-30 Tagen ab. Dies tritt erst nach mehreren Monaten ein, wenn man die zugeschmolzenen Röhrchen mit der Kultur statt im Ofen bei Zimmertemperatur aufbewahrt.

Die im geschlossenen Röhrchen abgestorbene Hefesaat kann $z u$ doppeltem Zweck, einmal zum Stuđium der Kulturbeläge, dann zu dem der löslichen Produkte dienen.

Die Beläge lassen sich leicht von der Oberfläche des Substrats abschaben und, in sterilisiertem Wasser verteilt, den Tieren einspritzen. Was die löslichen Produkte anbetrifft, so zerkleinert man den Nährboden mittels des Hofmeisterschen Apparates, verdünnt den Brei mit sterilisiertem Wasser und bedient sich zum Impfen der Spritze mit grober Nadel. Dieses Verfahren gewährt den Vorteil vollkommener Sicherheit, ausschliesslich lösliche Produkte einzuführen, welche die Mikroorganismen in vitro zubereitet hatten, da letzteren selbst die Fäbigkeit abgeht, in das lnnere des Nährmaterials vorzudringen.

$\mathrm{Zu}$ den besten Resultaten gelangte ich bisher durch Aussäen der Sprosshefen auf sterilisierter Kartoffel. Weniger aktiv fielen die Kulturen in mehr oder weniger konzentriertem Most, sowie in gewöhnlicher Fleischbrühe, auch wenn mit Glukose, Laktose, Dextrin oder Weinsteinsäure versetzt, auf Fucus crispus, Agar, Gelatine usw. aus. Das Aufsuchen von Kulturmethoden, die unter Herbeiziehen verschiedener Tier- und Pflanzensubstanzen zu ebenso aktiven Produkten verhülfen, wie die Aussaat auf Kartoffel, ist noch heute ein Gegenstand weiterer Forschung.

Alle die zahllosen Kontrollexperimente, das blosse Nährsubstrat zu verimpfen, wenn auch in ganz gleicher. Weise wie dasjenige, welches als Pflanzstätte pathogener Sprosshefen gedient hatte, führten konstant zu negativen Resultaten.

In einer anderen Arbeit behalte ich mir vor, die Ergebnisse von Experimenten mitzuteilen, die bezwecken, andere Produkte von Mikroorganismen auf Versuchstiere zu impfen, z. B. solche der gemeinen Blastomyceten der Luft und einiger gärender Flüssigkeiten, mehrerer pathogener und nicht pathogener Oidien, sowie pathogener und nicht pathogener Streptothricheen.

Ueber die Natur der in vitro bereiteten löslichen Produkte lässt sich nur wenig sagen. Es handelt sich nicht um Produkte gleicher Beschaffenheit wie die Enzyme, sie sind widerstandsfähig gegen Wärmegrade, denen letztere erliegen. Die Untersuchungsmethodik, welche die Chemie uns heute an die Hand gibt, ist zur Enthüllung der chemisehen Eigenheit dieser Substanzen noch zu grober Art, und viele Jahre dürften vergehen, bevor wir wissen, welcher Vorgang bei der Berührung der löslichen Pro- 
170 F. Sanfelice, Ueber die Wirkung der löslichen Produkte der Blastomyceten usw.

dukte mit Zellelementen stattfindet, ob es sich um eine rein physikalische Aktion des Kontakts, ob um Katalyse handelt, oder ob die Produkte in neuer Gestalt als Bestandteil des Protoplasmas in den Zellkörper eintreten.

II.

Anlässlich der jüngsten Experimente auf dem Felde der Verimpfung von Tieren der einen auf Tiere einer anderen Art und von Tier auf Tier derselben Spezies bemerkt Ribbert1) ganz richtig: "Die nenerdings so ausgedehnt vorgenommenen Uebertragungen von Tier zu Tier lenken ebenfalls von der Untersuchung der Genese menschlicher Tumoren ab. Und dabei Iehren sie uns nichts prinzipiell Neues. Handelt es sich bei ihnen doch um nichts anderes, als um die experimentell herbeigeführte Metastase auf einen anderen Körper derselben Spezies. Damit soll natürlich die Bedeutung der Versuche nicht überhaupt in Frage gestellt, es soll nur betont werden, dass sie uns über die erste Entstehung der Neubildungen nicht aufklären können."

In der Tat liegt wenig daran, ob die Geschwulstzellen an einem Tier imstande sind, sich auf einem anderen zu reproduzieren, höchst interessant dagegen ist es, die Ursache zu kennen, aus welcher der erstere Tumor sich entwickelt hat.

Damit die ätiologische Frage der bösartigen Geschwülste um einen Schritt vorwärts komme, heisst es vor allem, diese erste Unbekannte aufklären, den tieferen Grund der atypischen Zellvermehrung entdecken.

Das Bestreben, bösartige Tumoren experimentell vom Menschen auf Tiere zu verimpfen, datiert schon seit vielen Jahren her; bald gelang es, bald wieder nicht. Die ersten Versuche gelangten durch Langenbeck ${ }^{2}$ ) 1840 an die Oeffentlichkeit; Follin und Lebert ${ }^{3}$ ) spritzten in die Jugularis eines Hundes $60-70 \mathrm{~g}$ einer Emulsion von Brustkrebsteilchen in sterilisiertem Wasser und entdeckten nach 14 Tagen an den Wandungen des Herzens Krebsknötchen, in der Leber Tumoren von der Grösse eines Stecknadelkopfs. Weber ${ }^{4}$ ) impfte ein Oberkiefercarcinom in die Schenkelader eines Hundes ohne, Gouyon ${ }^{5}$ ) und Klencke ${ }^{6}$ mit positivem Resultat. Billroth's ${ }^{7}$ ) Versuche, Carcinome und Sarkome durch Impfen vom Menschen auf Hunde zu übertragen, schlugen fehl. Er mochte subkutane

1) Ribbert, Beiträge zur Entstehung der Geschwülste. Bonn 1906.

2) Langenbeck, Entstehung der Venenkrebse und die Möglichkeit, Carcinome von Menschen auf Tiere zu übertragen. Schmidts Jahrb. Bd. 25.

3) Follin und Lebert, Virchows Archiv. Bd. 11.

4) Weber, Chirurgische Erfahrungen. S. 289.

5) Gouyon, Jahresbericht über die Leistungen der gesamten Medizin. 1867.

6) Klencke, Häsers Archiv f. die ges. Medizin. Bd.. 4. 1843.

7) Billroth, Wiener med. Wochenschr. 1867. 
oder Jugular-Injektion vornehmen: nie bekam er ein Gedeihen des Experiments zu sehen. Reale ${ }^{1}$ ) nahm an einem Kaninchen die subkutane Einführung eines Stückehens idiopathisch-hämorrhagischen Hautsarkoms vor. Nach 2 Jahren begann die Entwickelung einer Geschwulst, die bis zu Kastaniengrösse anwuchs. Das mikroskopische Bild zeigte ein Bindegewebsstroma mit verästelten und anastomosierten Zellen. Im Stroma fanden sich Fibroblasten. Die Geschwulstzellen besassen einen grossen, ovalen, sehr tinktionsfähigen Kern. Zwei bis drei solche Zellen vereinigten sich zu Gruppen. Der Tumor erschien nur spärlich pigmentiert. Der Autor hielt die Geschwulst für ein Endothelialsarkom oder Lymphsarkom. Das Abweichen vom Originaltypus erklärt er mit dem Einfluss der neuen Terrainverhältnisse, wo sich die Geschwulst entwickelte. Vischer ${ }^{2}$ ) impfte ein Kauiuchen und ein Meerschweinchen mit wenigen Kubikzentimetern einer Emulsion von Melanosarkom in Kochsalzlösung in die Peritonealhöble. Nach 2 Monaten tötete er das Kaninchen und fand in der Bauchhöhle kleine schwärzliche Knötchen, aber keine Spur von Entzündung. Das Bindegewebe, aus welchem die Knötcben bestanden, wies Spindelzellen auf. Rückstände des eingebrachten Tumors fanden sich nicht vor. Identische Veränderungen waren am Meerschweinchen wahrzunehmen. Hier handelte es sich nicht um gelingende Ansiedelung der Geschwulst, sondern um Reaktion seitens des Netzes mit Pigmentzelleinschluss. Gaylord ${ }^{3}$ ). nahm an Hunden und Meerschweinchen Krebsimpfung vor. Bei einem Hunde ergab der Sektionsbefund das Vorhandensein zahlreicher kleiner Lebertumoren. Eins der Meerschweinchen wies ein carcinomatöses Knötchen an der Lunge auf.

Der Reihe oben zitierter Autoren, die sich mit dem Uebertragen bösartiger. Geschwülste des Menschen beschäftigt haben, füge ich zur Vervollständigung $\mathrm{L}_{\mathrm{ew}} \mathrm{in}^{4}$ ) bei, da er vor kurzem mit dem Verimpfen eines Menschentumors auf Hunde positive Resultate erzielte, die bis zur fünften Generation übergingen. Diese Arbeit überragt an Wichtigkeit alles, was bisher über den Gegenstand zu öffentlicher Kenntnis gelangte. Das vom Verfasser befolgte Verfahren gipfelt darin, dass er einem Hunde nach stattgefundener Laparotomie mehrere Stücke eines Ovarialcarcinoms in die Bauchhöhle einführte. Nach 3 Wochen tötete man das Tier. Am ganzen Peritoneum, namentlich über Netz und Gekröse zerstreut, zeigten sich un-

1) Reale, Tentativi d'inoculazione sperimentale del sarcoma cutaneo. Napoli 1902.

2) Vischer, Bruns' Beiträge. 1904.

3) Gaylord, The American Journal of the med. sciences. 1901.

4) Lewin, Ueber experimentell bei Hunden erzeugte verimpfbare Tumoren nach Uebertragung von menschlichem Krebsmaterial. Ztschr.f. Krebsforschg. 1906. 
172 F. Sanfelice, Ueber die Wirkung derlöslichen Produkte der Blastomyceten usw.

zählige Knötchen von Stecknadelkopfgrösse. Auch an Gallenblase und

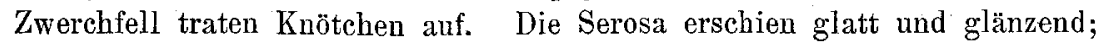
die retroperitonealen Lymphdrüsen etwas angeschwollen, von weicher Konsistenz, von Verkäsung keine Spur. Leber und Mliz bewahrten ihr normales Aussehen. Die Peritonealknötchen waren aus runden Zellen gebildet, dazwischen kamen aber auch uuregelmässige Kernformen und Spindelzellen vor. Die Zellkörper, aus denen die Neubildungen bestanden, hatten durchaus das Aussehen von Endothelialzellen. An den Knötchen war weder von Nekrose noch von vorhandenen Riesenzellen etwas zu bemerken. Knötchen traten auch im Fettzellengewebe auf, dessen Stroma Anhäufung von ganz den oben beschriebenen ähnlichen Zellen enthielt. Die Lymphzellen boten im allgemeinen den Habitus der entzündeten Mandeln. Hier und da stiess man auf Gruppen grösserer, zum Teil mehrkerniger Zellen. Histologisch differierte der Prozess kaum merklich von dem Verlaufe einer beliebigen Entzündung. Mit den Knötchen des ersten Hundes impfte man sodann zwei andere in dje Bauchhöhle. Die an diesen letzteren Versuchstieren hervorgebrachten Veränderungen unterschieden sich deutlich von den gewöhnlichen, durch physikalische oder chemische Reize erzeugten Entzündungserscheinungen. Durch Einführen fremder Körper verschiedener Art führt man am Bauchfell Granulome, sogenannte fremde Körpertuberkeln herbei, die sich nicht von Hund auf Hund übertragen lassen. Es fehlt somit an jeglicher Analogie zwischen diesen und den von Lewin erzielten Krankheitserscheinungen. Bis zur fünften Generation gelangen die Uebertragungsoperationen des Autors, wobei selbst an Leber und Lunge der Hunde neoplastische Formationen auftraten. Liessen die an den ersten Versuchstieren hervorgebrachten Veränderungen sich von Erscheinungen entzündlicher Natur nicht unterscheiden, so trugen die Neubildungen, die an den anderen zum Vorschein kamen, ganz deutlich den Stempel sarkomatöser Beschaffenheit zur Schau.

Lewins Experimente gewinnen an hoher Wichtigkeit noch besonders durch einen speziellen Umstand. Während beim Uebertragen der Geschwülste von Tier auf Tier der gleichen Spezies, wie wir in der Folge sehen werden, die Zellen der an Versuchstier B erzeugten Tumoren nicht aus den seinem Organismus angehörenden, sondern aus Zellkörpern des Tieres A besteben, so liegt die Sache bei den Lewinschen Versuchen ganz anders. Die Neubildungen, die an den Hunden der zweiten, dritten, vierten und fünften Generation zu Tage treten, verdanken ihren Bau nicht der ungeimpften Ovarialgeschwulst, sondern sie bestehen aus Zellen des Organismus, auf den sie übertragen wurden. Wollten wir das nicht zugeben, so bliebe nur eine Hypothese übrig, dass nämlich die Epithelzellen, woraus der Tumor des Eierstocks sich aufbaute, eine Transformation in Zellen endothelialer Natur erlitten baben, wie wir sie als Bestandteile der 
an den Hunden beobachteten Veränderungen zu sehen bekamen; eine durchaus unzulässige Annahme. Die neoplastischen Zellkőrper des Ovariums reizten mittels eines quid, das sie enthielten, die Zellen der Peritonealserosa der Hunde zur Vermehrung und Bildung lokaler und auf Distanz (in Leber und Lunge) auftretender Geschwulstknötchen. Lewins Experimente erhalten daher eine Bedeutung als Beweismittel für ein echtes lnfektionsvermögen der neugebildeten Zellen, ein Umstand, den die Autoren der übrigen Tumoren-Impfexperimente der Neuzeit absolut ausschliessen. Dass die Zellen der bösartigen Geschwülste etwas dem Organismus fremdes an sich haben (Bichat), ist bekannt, nämlich die Eigensichaft, auf das Stroma einen gewissen Reiz auszuüben, was man aus der Gegenwart von Riesenzellen im Stroma einiger Carcinome schloss, unbekannt dagegen war diese ihnen innewohnende Fähigkeit, andere Zellelemente zur Vermehrung anzureizen, die bis zur Bildung echter Neoplasien führen kann. Dieses Faktum stimmt vollständig mit den Beobachtungen überein, die ich nach dem Impfen der löslichen Produkte von Sprosshefen in den Unterleib von Hunden gemacht habe.

Zablreiche Arbeiten über das Verimpfen maligner Tumoren von Tier zu. Tier der gleichen Spezies wurden in den letzten Jahren veröffentlicht. Sticker ${ }^{1}$ ) gelang die Reproduktion ciner Sarkomform durch mehrere Generationen von Hunden. $\mathrm{Hana}^{2}$ ) hatte schon 1889 an Mäusen maligne Tumoren hervorgebracht und in der Folge brachten auch Jansen ${ }^{3}$ ), Michaelis ${ }^{4}$ ) und Andere ${ }^{5}$ ) denselben Versuch zustande. Wie schon gesagt, tragen diese Experimente aber nichts Neues zu unserer Belehrung bei und förderten die bedeutsame Frage nach den Krankheitsursachen des Krebses um keine Elle. Alle jene Forscher hätten besser daran getan, statt Geschwülste von Tier auf Tier zu übertragen, der Art und Weise nachzuforschen, wie durch Impfen bekannter Keime diesen für bösartige Geschwülste so äusserst empfänglichen Tieren der Krebs beigebracht wird.

III.

Ich gebe zu der Beschreibung von 13 Impfversuchen, die ich an Hunden vornahm, über.

1) Sticker, Transplantables Rundzellensarkom des Hundes, Zeitschr. f. Krebsforschung. 1905-1906.

2) Hanau, Uebertragung von Carcinom. Langenbecks Archiv. Bd. 39.

3) Jensen, Experimentelle Untersuchungen über Krebs bei Mäusen. Zentralblatt f. Bakteriol. Bd. 34. 1904.

4) Michaelis, Experimentelle Untersuchungen über den Krebs der Mäuse. Med. Klinik. 1905.

5) Arbeiten aus dem kgl. Institut f. experiment. Therapie zu Frankfurt a. M. Jena 1906. 
174 F. Sanfelice, Ueber die Wirkung der löslichen Produkte der Blastomyceten usw.

Die drei ersten Hunde erhielten Abdominaleinspritzungen der Produkte für sich allein, vier andere in der gleichen Region die Parasiten und Produkte vereint; drei weitere Hunde nur die Produkte, und zwar in das subkutane Bindegewebe beigebracht. Von den letzterwähnten drei Versuchstieren impfte man zwei in das subkutane Bindegewebe der Vorhaut, das dritte in der Umgebung einer Mamilla. Die übrigbleibenden drei Hunde empfingen endovenale Impfung der Parasiten und Produkte zugleich.

Bei den drei Versuchstieren, die mit den Produkten ohne Kulturbelag in die Bauchhöhle geimpft waren, fielen die Resultate durchweg positiv aus. Dabei sei als bemerkenswert die Tatsache hervorgehoben, dass, sämtliche Experimente, wo zu abdominalem Impfen der Hunde ausschliesslich Parasiten in Anwendung kamen, stets negativ ausfielen. Für das erste der mit löslichen Produkten an der Bauchhöhle operierten Tiere diente als Impfmaterial die Kultur einer vor mehreren Jabren aus einem infektiösen Papillom des Eierstocks isolierten Hefe, die, im geschlossenen Röhrchen ausgesät, vier Monate lang im Thermostaten verblieben war; der Hund verendete nach einem Monat, eine Beute auffallender Kachexie. Sektionsbefund: Im grossen Netz ein Tumor rom Umfang eines Taubeneies und über die ganze Region ausgesäte Knötchen verschiedener Grösse; starke Anschwellung der Mesenteriallymphdrüsen, endlich am oberen Teil der Leber (Tafel I, Fig. 5) über die Oberfläche zerstreut und etwas darüber hervorragend, viele rundliche und ovale Platten von unregelmässiger Gestalt mit gewellten Rändern, von gelblichweisser Farbe. Senkrecht auf die Basis dieser Platten ausgeführte Schnitte zeigten, dass sie nur oberflächlich auflagen und nicht tiefer in das Parenchym des Organs eindrangen. Neubildungen von demselben Aussehen kamen, doch weniger zahlreich, an der Unterseite des sehnigen Diaphragmazentrums zum Vorschein. Die Bauchhöhlenserosa zeigte kéine Spur von Entzündung und war glatt und glänzend. Zwischen den Organen des Abdominalraums fand keine Adhäreuz statt. An Nieren und Milz mit blossem Auge nichts wahrzunehmen. Beim Durchschneiden der Lunge zeigten sich, besonders häufig. in den unteren Flügeln zerstreut, Flecke von gelblicher Farbe.

Kulturen, die durch Aussïen von Bruchstücken der Milz, Leber und der Netzknötchen auf Agar, Gelatine und Kartoffeln versucht wurden, hatten negativen Erfolg:

Die Hauptgeschwulst im grossen Netz erscheint histologisch als Aufbau von protoplasmatischen Zellen mit bläschenförmigem, leicht tingierbarem Kern. Letzterer liegt bei einigen Zellen im Protoplasmazentrum, bei anderen zeigt er sich gegen die Peripherie verschoben. Die Protoplasmakörper sind ohne sichtbare Interzellularsubstanz aneinandergereiht. Mehr oder weniger ansehnliche Zellengruppen trennt spärliches, hier und da leicht infiltriertes Bindegewebe. 
Mitten unter den beschriebenen Zellgruppen treten Cystenformationen auf, bestehend aus den gleichen Zellen in strahlenförmiger Anordnung um einen Mittelpunkt, den entweder eine amorphe oder angebäufte hyaline Substanz mit mehr oder weniger grossem Ueberfluss an Zellkern-Detritus einnimmt. In den Serienschnitten dieser Cystengebilde geht im Aussehen der Zellen, je nachdem der Schnitt sich der Peripherie oder dem Zentrum nähert, eine Veränderung vor. Während ihre Anordnung in hart an der Aussenseite gemachten Schnitten ganz identisch ist mit derjenigen der Zellen, woraus die Hauptmasse der Geschwulst besteht, nehmen sie in den Schnitten vom zentralen Teil Zylinderform an und umgeben mehrschichtig, die einen hart an die anderen gedrängt, strahlenartig den Mittelpunkt des Gebildes.

Zwischen mehrere dieser Cystenneubildungen und das Gewebe, das den Hauptteil der Geschwulst ausmacht, schieben sich eine oder mehrere Schichten von Spindelżellen, anderswo besorgen diese Trennung vom Rest des Tumorgewebes einige Lagen von Zellsträngen, die ganz wie die Geschwulstzellen, nur abgeplattet, aussehen. Je nach mehr oder weniger vorgerücktem Alter bieten die Aussenteile dieser Neubildungen eimen veränderten Anblick. Es handelt sich um einen Transformationsprozess: die hart an die Cystengebilde anstossenden Zellen des Tumors wandeln sich, mit dem Bestreben, deren Ausdehnung Schranken zu setzen, in spindelförmige Bindegewebszellen um.

Die über das grosse Netz zerstreuten Knötchen sind von gleicher Struktur, wie die Hauptgeschwulst.

Ebenso stimmt die Struktur der an der Leberoberfläche befindlichen Platten (Tafel I, Fig. 7 und Tafel I, Fig. 10) mit dem Bau der oben beschriebenen Tumoren überein, nur mit dem Unterschied, dass Cystenformationen viel häufiger auftreten. Wie man aus Serienschnitten dieser Platten ersieht, haften diese nicht in ihrer ganzen Länge und Breite, sondern nur mit einem beschränkten Teil ihrer unteren Seite an der Leberkapsel. Die Adhäsion übernimmt ein Bindegewebe, in dessen Mitte sich die überwucherten Zellen der Serosa deutlich unterscheiden Jassen. Wo die Neubildung nicht direkt an der Leber adhäriert, erscheinen die Serosazellen zylindrisch, nehmen aber, je weiter sie sich von der Berührungsstelle entfernen, mehr und mehr ihr normales Aussehen an.

Der Aufbau der Cystenformation, wie sie in den Leberneubildungen auftritt, zeichnet sich vor demjenigen der Hauptgeschwulst durch bestimmter definierte Anordnung aus. Je nachdem ein Schnitt von der Peripherie oder von der Mitte näherliegenden Partien herrührt, erscheinen die Zellen verlängert, zylindrisch, schichtenweis gelagert mit ausgesprochener Strahlendisposition. Diese Zellschicht, woraus die Cystenwand besteht, erreicht nicht überall die gleiche Höbe, hier ist sie beträchtlich, dort 
176 F. Sanfelice, Ueber die Wirkung derlöslichen Produkte der Blastomyceten usw.

wieder geringer. Auch in der Grösse variieren diese Gebilde ungemein. Nur selten bekam ich, nahe an der Aussenseite einiger Cysten, Riesenzellen zu sehen, ihre Zellkerne lagen dicht am Zentrum, während ein Hof freien Protoplasmas sich gegen die Peripherie ausdehnte.

Den gleichen Anblick bieten übrigens auch die zwischen den Cystenbildungen eingeschobenen Gewebszellen, sowie die ausgesprochene Teńndenz, jene wie mit einer Ringmauer gegen aussen abzuschliessen. Doch kehren auch sie hier und dort zu der Anordnung und Gestalt der dem Hauptgewebe der Geschwulst eigentümlichen Zellformen zurück.

Regressive Phasen kamen weder an den Neubildungen der Leber noch im Haupttumor zum Vorschein.

Wo keine Neoplasien zu sehen sind, erscheint das grosse Netz etwas verdickt, es findet dort mehr oder weniger reichliche Infiltration von Zellen statt, die gleichfalls den Charakter der am Gefüge der Hauptgeschwulst teilnehmenden Formen zeigen.

Dagegen ist die Struktur der Neubildungen an der unteren Seite des Zwerchfells identisch mit derjenigen, welche sie in der Leber aufweisen.

Cystenneubildungen gleich den weiter oben beschriebenen finden sich einzeln und gruppenweise auf einigen Stellen der Peritoneumoberfläche des Dünndarms und zwar im Bindegewebe, welches das Pankreas und die Nieren einhüllt.

Im Leberparenchym stösst man bisweilen auf kleine Zellflecke von der gleichen Art, die den Haupttumor auszeichnet; bald sind die Elemente scharf von einander abgegrenzt, bald verschmelzen ihre Protoplasmakörper. Den Aussenrand solcher Flecke besetzen hier und da abgeplattete Endothelialelemente, ein Beweis, dass diese Zellgruppen in den Kapillaren ansässig sind.

Nieren und Milz blieben von Veränderungen durchweg verschont.

In den retroperitonealen Lymphdrüsen treten, namentlich nach dem Rande unter der Capsula zu, mehr oder weniger ansehnliche Gruppen von Zellen auf (Tafel I, Fig. 8), von Natur ganz identisch mit denen, welche man in der Hauptgeschwulst und im Leberparenchym antrifft. An die Stelle der Mandelsubstanz ist in einzelnen Lymphdrüsen grossenteils, bei anderen ganz und gar das Gewebe der Neubildung getreten, sodass die Struktur der Lymphdrüsen nur an seltenen Ueberbleibseln lymphartigen Gewebes erkembar ist.

In der Lunge finden sich, besonders da, wo die Bindegewebswandung der Blutgefässe in Betracht kommt, bald mehr, bald weniger ausgedehnte Zellstränge von der dem Haupttumor eigenen Art und treten die schon früher erwähnten metastatischen Erscheinungen auf (Tafel II, Fig. 1). Dafür kam mir weder bei diesen Gewebsneubildungen des Leberparenchyms, noch bei denen der Lymphdrüsen, noch in denen der Lunge jemals eine 
Spur von Cystenbildung zu Gesicht, identisch mit den im Haupttumor und an der Oberfläche von Leber und grossem Netz angetroffenen.

Der zweite von den bloss mit Produkten von Saccharomyces canis II in die Bauchhöhle geimpften Hunden starb nach 56 Tagen. Der Sektionsbefund lautet: Im grossen Netz ein Tumor vom Umfang einer Kastanie und spärlich über dasselbe Organ zerstreute Knötchen; Anschwellung der Abdominallymphdrüsen; an Leber und Milz nichts Erwähnenswertes. Gelblichweisse Flecke zeigen sich an der Rindensubstanz der Nieren und greifen stellenweise durch deren ganze Dicke. An den Lungen nichts Bemerkenswertes. Die Serosa frei von jeglicher Spur etwaiger Entzündung.

Der Haupttumor im grossen Netz zeigt das gleiche Gefüge, wie der am vorigen Hund gesehene, doch mit dem Unterschied, dass, während bei dem ersten Versuchstier die Hauptmasse der Geschwulst aus Zellgruppen mit reichlichem Plasma und Bläschenkern bestand und Cystenformation nur spärlich daran teilnahm, bei diesem zweiten Hunde Cystengebilde weitaus den grössten Teil der Geschwulst in Anspruch nahmen, sodass für Zellgruppen, wie wir sie vorhin beschrieben, nur ein geringes Feld übrig blieb. Die eigentlichen, wie früher erwähnt, bald in grössere, bald in kleinere Gruppen verteilten Geschwulstelemente trennen mehr oder weniger dicht zusammengedrängte Büschel des Bindegewebes, wie an der anderen Geschwulst von Blutgängen durchzogen. Was die Cystenformationen und die Eigentümlichkeiten ihrer Struktur betrifft, so verweise ich auf die weiter oben gegebene Beschreibung; ibr Anblick in den Serienschnitten wechselt auch hier, je nachdem dieselben von der Peripheriepartie oder aus der Zentrumsregion herrühren.

Im Fettgewebe des grossen Netzes (Tafel I, Fig. 6), im Bindegewebe, das dem Pankreas (Tafel II, Fig. 2) bzw. den Nieren als Mantel dient, treten Neubildungen in Hülle und Fülle auf; bald stimmen sie mit den im Haupttumor beobachteten Cystenformationen überein, bald gibt die ganze Schnittserie ein Bild fester Mandelformation ohne Zentralraum, indem die Zellelemente zu bald grösseren, bald kleineren, durch spärliche Bindegewebsfasern von einander getrennten Haufen geordnet, das Gerüst bilden.

Die Bauchlymphdrüsen weisen, abweichend von den am ersten Hunde gemachten Beobachtungen, keine aus den der Hauptgeschwulst eigentümlichen Zellelementen bestehenden Neoplasien auf. An Leber und Milz ist nichts Erhebliches zu sehen.

Dagegen kommen in der Nieren-Rindensubstanz Neubildungen zum Vorschein, zu denen Zellkörper von gleicher Natur wie die, woraus der weniger stark entwickelte Teil der Hauptgeschwulst besteht, das Material liefern; auch zeigen sich an der Peripherie dieser Gebilde zahlreiche 
178 F. Sanfelice, Ueber die Wirkung der löslichen Produkte der Blastomyceten usw.

Sektionen von Harnkanälchen mit jungem Epitel, das sich von Deckzellen auf normalen Harnkanälchen ganz auffallend unterscheidet.

Die Lungenschnitte bieten nichts von Bedeutung.

Der letzte von den drei ausschliesslich mit den Produkten von Saccharomyces canis II an der Bauchhöhle geimpften Hunde starb nach 15 Wochen. Sektionsbefund: ein hühnereigrosser Tumor im grossen Nétz (Tafel I, Fig. 2) und viele über die Region ausgestreute Knötchen. Bedeutende Anschwellung der Bauchlymphdrüsen. Leber und Milz normal. Die Niere, wie am vorhergehenden Versuchstier beschrieben, mit einer Menge die Rindensubstanz durchsetzender Neubildungen behaftet. Lungen im Normalzustand:

Was das Gewebe betrifft, so erscheint die Hauptgeschwulst von gleicher Struktur, wie die am ersten Hund untersuchte. Dafür erregt der histologische Befund einiger Abdominallymphdrüsen in bohem Grade unsere Aufmerksamkeit, indem sie Neubildungen von identischem Bau wie die Cystenformationen des Haupttumors vorweisen (Tafel II, Fig. 3). Den Mittelpunkt dieser Art Balggeschwulst nimmt eine hyaline, mit reichlichem Zellkern-Detritus versetzte Substanz ein. Die an der Niere auftretenden Neubildungen stimmen, was die Struktur betrifft, ganz mit den am zweiten Versuchstier beschriebenen überein. Weder das Aussehen der Leber, noch das der Milz, noch das der Lunge gibt zu Bemerkungen Anlass.

Von den mit vier Hunden angestellten Versuchen, gleichzeitig lebende Parasiten und Produkte in den Abdominalraum zu injizieren, führten drei zu positiven Erfolgen. Das vierte Tier wurde nach einigen Monaten getötet; es trat keinerlei Veränderung zutage.

Der erste Hund war 50 Tage nach dem Impfen verendet. Bei der Sektion nahm man mehrere Tumoren im grossen Netz, sowie mässige Anschwellungen an Gekröse und Lymphdrüsen war, dagegen nichts an Leber, Milz und Niere. Die Lunge zeigte kleine hepatisierte Flecke.

Die Netzgeschwülste waren von gleicher Struktur wie die früher untersuchten. In den Abdominallymphdrüsen entdeckte ich nichts, was Metastasen ähnlich sah. Dagegen gewahrte man in dem das Pankreas umgebenden Bindegewebe kleine Knötchen solchen Ursprungs. An Leber und Milz nichts Auffallendes. Die Lunge war von Metastasen gleicher Natur wie diejenigen der hauptsächlichen Geschwülste befallen.

Die anderen zwei Hunde starben nach 48 bzw. 65 Tagen mit identischem Befund, sei es in anatomisch-pathologischer wie in histologischer Hinsicht. Zwei meiner früheren Arbeiten ${ }^{1}$ ) brachten die Beschreibung von Ge-

1) Sanfelice, Ueber die pathogene Wirkung der Blastomyceten. V. Abhandlung. Zeitschr. f. Hygiene. 1898. - Ueber die pathogene Wirkung der Blastomyceten. VI. Abhandlung. Zeitschr. f. Hygiene. 1903. 
schwulsterscheinungen an der Präputiummukosa von zwei Hunden. Das eine Tier hatte man mit Reinkultur einer pathogenen Sprosshefe subkutan in. der Hodengegend geimpft; bei der nach 5 Monaten vorgenommenen Sektion zeigte sich an Stelle der Testikel eine gelblichweisse Masse neugebildeten Gewebes von ziemlich weicher Konsistenz, während den Penis eine Menge Knötchen von gleichem Aussehen wie die Hauptmasse der Geschwulst umgab; die Extremität des Gliedes steckte in einer kegelförmigen Neoplasmamasse. Der zweite Hund, der in gleicher. Weise und gleichfalls in der Umgebung der Hoden geimpft.war, starb nach 4 Monaten und wies eine aus mehreren Kuötchen verschiedener Grösse bestehende Geschwulst im subkutanen Bindegewebe der Vorhaut auf. Die an letzterem Versuchstier gemachte Beobachtung einer aus dem Präputiumbindegewebe entwickelten Geschwulst gab den Grund zu der Diagnose auf Sarkom:

Aus einer so bescheidenen Anzahl von Wahrnehmungen liess sich die Histogenesis dieser Geschwülste sicher nicht herleiten. Dank zwei weiteren Fällen ganz gleicher Tumoren, die mir in den letzten Monaten vorgekommen sind, konnte ich jedoch den Entstebungsmodus solcher Neoplasien mit Gewissheit feststellen.

Betrachtet man die Vorhautmukosa des normalen Hundes näher, so fallen sowohl an der Oberfäche als im Innern der Schleimhaut stecknadelkopfgrosse, etwas vorstehende, weissliche Knötchen auf. An senkrecht auf die Haut vorgenommenen Serienschnitten ist deutlich zu erkennen, dass diese Knötchen ihr Entstehen einer Anhäufung von Lymphelementen verdanken, wodurch das Bekleidungsepithel der Mukosa etwas in die Höbe gedrückt wird. Das Fehlen von Scheidewandepithel, die Abwesenheit von Abfuhrkanälen, die Aehnlichkeit der Zellen, woraus sie bestehen, mit Lymphelementen, schlieșsen den Gedanken, man könnte es mit eigentlichen Drüsen zu tun haben, a priori aus, während die Annahme, es handle sich um kleine Lymphfollikel, sehr an Wahrscheinlichkeit gewinnt. Die bereits bescbriebenen Tumoren und andere, von welchen sogleich die Rede sein wird, nehmen ibren Ursprung von den Zellelementen, aus denen solche Formationen sich aufbauen.

Der eine, nur mit Produkten von Saccharomyces canis II in das subkutane Bindegewebe der Penisgegend geimpfte Hund wurde nach 1 Monat getötet, wobei es sich herausstellte, dass die soeben erwähnten kleinen Knötchen, besonders auf der Mukosa der Vorhautwandung, bedeutend angeschwollen waren. Anfänglich konnte man keinen Zusammenhang zwischen der ansehnlichen Anschwellung und der stattgehabten Injektion finden und nahm daher an der Vorbautmukosa sämtlicher im städtischen Hundestall getöteten Tiere eine Untersuchung vor. Bei keinem einzigen war die gleiche Wahrnehmung zu machen. Bei dem geimpften Hund (Tafel I, Fig. 9) betrug das Volumen der Knötchen die vierfache Normalgrösse und, während 
180 F. Sanfelice, Ueber die Wirkung derlöslichen Produkteder Blastomyceten usw.

auf normaler Schleimhaut das eine vom andern deutlich gesondert und jedes unter Beibehaltung der runden Form erschien, traten sie, wemn Impfung stattgefunden, in zusammenhängender Ordnung auf, sodass die abgeplatteten Seitenflächen zusammenstiessen und die Knötchen ihre runde Form verloren.

Die Schnitte dieser Kuötchen zeigen mitten unter den Lymphelementen die charakteristischen Zellen der Evolutionsneoplasie, die, zu grösseren oder kleineren Gruppen vereinigt, von Infiltrationselementen umgeben sind.

Der andere Hund, dem man in der Nähe des Penis subkutan die Produkte der genaunten Sprosshefe eingeführt hatte, starb nach 15 Wochen. Hier erschien auf der Mukosa der Vorhautwand (Tafel I, Fig. 1) ein Tumor von der Grösse eines kleinen Hühnereies mit blumenkohlartig zerklüftetèr Oberfläche. An den Hoden war keine Veränderung zu bemerken, ebensowenig an den Organen der Bauchböhle. Auch die Lunge befand sich im Normalzustand.

In Schnitten, die man an der Geschwulst ausführte, kamen unter dew Schleimhautepithel die dem Tumor eigentümlichen Elemente zum Vorschein, bestehend aus gleichmässig gestalteten Zellen mit intensiv gefärbtem Zellkern und nicht deutlich gesonderten Protoplasmakörpern (Tafel II, Fig. 6). Nicht wenige dieser Geschwulstelemente befanden sich im Zustand atypischer Mitosetrennung. Spärliche Bindegewebsfasern trennten melrr oder weniger ansehnliche Gruppen neugebildeter Zellen voneinander. Das Schleimhautepithel wird durch die Vermehrung der Geschwulstelemente ganz ausserordentlich ausgedehnt, was zu allen den Zerklüftungen Anlass gibt und der Oberfläche der Neubildung ein blumenkohlartiges Aussehen verleiht.

Die Deckzellen der Schleimhaut nehmen somit an der Bildung der Geschwulst nicht aktiven Anteil.

Die histologische Diagnose lautet auf rundzelliges Sarkom. Ich bin der festen Veberzeugung, dass ein Tumor gleicher Natur Sticker als Beobachtungsobjekt vorlag und von ihm in zahlreichen Impfexperimenten durch eine ganze Reihe von Generationen von Hunden hindurch fortgepflanzt wurde.

Im Laufe von ungefähr 4 Jahren hatte ich noch zweimal Gelegenheit, dieses Penissarkom zu beobachten, das sich an zwei im städtischen Hundestall getöteten Jagdhunden spontan entwickelt hatte. In dem einen Fall war der Tumor voluminöser als der oben beschriebene und eiterte an verschiedenen Stellen. Im zweiten Fall hatte die Penisgeschwulst die gleiche Grösse wie der beschriebene. Während bei dem ersten Tier die Leistendrüsen und die Organe der Bauch- und Brusthöhlen keine Metastasen aufwiesen, traten bei dem zweiten solche in den Abdominallymphdrüsen und in der Leber auf. Erstgenamnte Mandeln waren ganz bedeutend angeschwollen und gänzlich aus neugebildeten Elementen aufgebaut. In der 
Leber zeigten sich Knoten verschiedenen Umfangs, von Haselnuss- bis zu Erbsengrösse, bald an der Oberfläche, bald tief im Innern; histologisch bestand ihr Bau aus den gleichen Rundzellen der Hauptgeschwulst. Diese letzte Beobachtung zerstört jeden Zweifel an der Sarkomnatur der Neubildung, welche an dem mit den löslichen Produkten von Saccharomyces canis II in das dem Penis naheliegende subkutane Bindegewebe geimpften Hunde zum Vorschein kam.

Eine weitere subkutane Injektion ausschliesslich löslicher Produkte der genannten Pilze (Saccharomyces canis $I$ ) wurde an einer alten Hündin in der Nähe einer Brustwarze vorgenommen. Zur Kontrolle fand an zwei naheliegenden Mamillen das Einspritzen einer sterilisierten Kartoffelemulsion in Wasser statt. Mehrere Tage nach der Operation war an der mit löslichen Produkten infizierten Warze eine Verdickung wabrzunehmen, die nach 3 Monaten Kastaniengrösse erreichte. Als der Tumor der Mamilla 5 Monate nach der Impfung den Umfang eimes Hühnereies zeigte, wurde das Tier getötet. An den beiden nur zur Kontrolle geimpften Brüsten war nichts" zu sehen.

An den Abdominalorganen förderte die Sektion keine Veränderungen zutage. Dagegen erschien die Lunge, sowohl aussen als im Parenchym, reichlich von Knötchen heimgesucht; die kleiusten hatten nur Stecknadelkopfgrösse, die ansehnlicheren, von denen einige erbsengross waren, ragten etwas über die Oberfläche des Organs hervor und trugen in der Mitte eine leichte Vertiefung. Ihr Gewebe erschien in den Schnitten kompakt und von weisser Farbe.

Histologisch wies die Mamillargeschwulst die Struktur eines Adenocarcinoms auf, während der Bau der Pulmonarneubildungen mit dem des Haupttumors identisch war (Tafel II, Fig. 4). Die adenomatöse Natur der Neoplasie kam an der Mamillargeschwulst mit grösserer Evidenz zur Geltung, als bei den Lungenmetastasen. Bei letzteren traten die jungen Elemente schollenförmig in grösseren oder kleineren, von Bindegewebsfibrillen getrennten Komplexen auf. An gewissen Stellen begünstigte die Metastasen die Röhrendisposition der neoplastischen Elemente, doch weniger deutlich als im Haupttumor.

Von 10 Experimenten, Hunde nur mit den Produkten pathogener Sprosshefen oder mit Produkten und Parasiten gemeinsam, sei es am Unterleib sei es im subkutanen Bindegewebe zu impfen, ergaben 9 positive Resultate. Ein glänzender Erfolg gegenüber der früheren Praxis, wo mit Injektion der Parasiten nie auch nur aunähernde Zahlenverhältnisse zu verzeichnen waren.

Zur Vervollständigung der Reihe mit Hunden angestellter Versuche füge ich das Ergebnis der endorenösen Einführung von Produkten und Parasiten bei. Ich bediente mich zu diesem Zweck der 2 Monate bei 
182 F. Sanfelice, Ueber die Wirkung derlöslichen Produkte der Blastomyceten usw.

Zimmertemperatur aufbewahten Kultur von Saccharomyces can is II in geschlossenen Röhrchen. Eine mit sterilisiertem Wasser bereitete, äusserst dünnflüssige Emulsion der Kultur wurde in kleiner Dosis in die Jugularvene eingespritzt. Unter dem Druck, den die Flüssigkeit ausübte, erschienen die Tiere unmittelbar nach ihrer Befreiung rom Operationstisch niedergeschlagen, erholten sich jedoch nach wenigen Minuten und gaben in den nächsten Tagen kein Zeichen eines anormalen Zustandes.

Von drei operierten Hunden starb der erste nach 26, der zweite nach 30 und der dritte nach 42 Tagen; bei allen äusserten sich die gleichen Krankheitserscheinungen.

Die wichtigsten treten in der Leber, den Nieren, den Bauchlymphdrüsen, in der Lunge und am Gehirn auf. Bei einem der Tiere konstatierte ich auch eine Beschädigung des Pankreas. Die Leber ist aussen und innen reichlich mit gelblichen Flecken besetzt. Dieselbe Art von Neubildungen hat sich auch der Rinden- und Marksubstanz der Nieren bemächtigt. Die Unterleibslymphdrüsen sind stark angeschwollen. Die Milz hat ebenfalls an Volumen zugenommen und bei der Sektion erscheinen die Follikel angeschwollen. Am Pankreas stechen vom rosaroten Grund eine Menge gelblichweisser Flecke ab und mit gleichen Neubildungen ist die Lunge an der Oberfläche wie durch das ganze Parenchym wie besät. Im grossen wie im kleinen Hirn bleibt weder die weisse noch die graue Substanz davon verschont.

Es handelt sich um diffuse Neoplasien; von den gleichen Zellelementen ausgehend, die bei den am Unterleib geimpiten Hunden die Hauptgeschwulst aufbauten, verbreiten sie sich hier über sämtliche Organe. Die Leber ist manchmal mit den Gebilden dermassen vollgepfropft, dass man sagen möchte, es sei mehr neoplastisches Gewebe vorhanden, als hepatisches (Tafel II, Fig. 7). Riesenzellen und regressive Metamorphosen kommen nicht zum Vorschein. An und für sich hat das Gewebe des Organs ein durchaus normales Aussehen, nur in der Nähe der jungen Formation findet leichte Infiltration statt. Den gleichen Neubildungen wie in der Leber begegnet man in den Nieren, besonders reichlich in der Rinden-, seltener in der Marksubstanz. Auch in der Milzpulpa gibt es Stellen neugebildeten Gewebes, vorzugsweise in den Maschen des Netzwerks, wie auch in einzelnen Follikeln kleine Gruppen "neoplastischer Zellen auftreten. Manche Lymphdrüsen bestehen fast ausschliesslich aus dem jungen Gewebe, an anderen zeigen sie sich plattenweise, mehr oder weniger ansehnlich gegen die Peripherie hin. Pankreas und Netz weisen die gleichen Neubildungen auf, In der Lunge findet man sie am häufigsten in der Nachbarschaft der Luftröhrenäste und die kleinen Schlagadern und Venen sind vielfach von Flecken neugtbildeten Gewebes umgeben. Auch unter der Pleura siedelt sich hier und da ein Knoten von 
derartiger Beschaffenheit an. Die im grossen und kleinen Hirn auftretenden Neubildungen stehen in Verbindung mit den Blutgefässen.

Die an Hunden durch endovenöses Impfen nur mit Parasiten herbeigeführten Veränderungen differenzieren von den obenbeschriebenen insofern, als letztere eine stärkere Diffusion der Neubildungen aufweisen. Die Zahl von Parasiten, die im Organismus der zugleich mit Pilzen und Produkten geimpften Hunde auftritt, ist so karg zugemessen, dass es mir nie gelang, sie nochmals in Kulturen aufwachsen zu sehen.

Ueber die Natur der Veränderungen habe ich mich schon in meinen früheren Arbeiten ausgesprochen, ich halte sie für sarkomatöse Neubildungen.

IV.

Bevor wir weiter gehen, sind einige Betrachtungen über die Befunde angebracht, zu welchen abdominales Impfen der löslichen Produkte von pathogenen Blastomyceten führte. Vor allem eine bestimmte Antwort auf die Frage: gehören die beschriebenen Veränderungen der Kategorie der Granulationsgeschwïlste an, oder sind es echte Tumoren?

Der Bau der ersteren ist ein so mannigfaltiger, dass man sie mit Leichtigkeit von echten Tumoren differenzieren kann. Die Uebereinstimmung in der Verbreitungsart durch Metastasen ist nur eine scheinbare. Die Tuberkel, die Aktinomykose, die Gummigeschwulst, die Rinder-Perlsucht und tine ganze Reihe anderer Krankheitsprozesse zeichnen sich vor den echten Tumoren insofern aus, als die Metastase tatsächlich von der Uebersiedelung des Parasiten vom ursprünglichen Sitz auf andere Körperteile herrührt, wo er das dort befindliche Gewebe zum Wuchern reizt. Auf solche Weise entstehen mit den primitiven identische Neubildungen, weil das im ganzen Organismus verbreitete Bindegewebe das Material dazu liefert. Gibt jedoch ein Chondrom Veranlassung zu Metastasen, so treffen wir das gleiche kartilaginöse Gewebe, an welchem Organ sie immer stattfinden mag. Diese Metastasen rühren somit von Bestandteilchen der Originalgeschwulst her, die, von den Lymph- und Blutströmen mitgerissen, ihre Wanderung antreten. Handelt es sich um Granulationsgeschwülste, so findet eine Metastase des Parasiten, im Falle echter Tumoren die der Zellelemente der Geschwulst selber statt.

Sind nun, wie wir oben sahen, die echten Tumoren nicht mit Granulations-Geschwülsten zu verwechseln, so gibt es immerhin Fälle, wo die Unterscheidung mit Schwierigkeiten verbunden ist, besonders da, wo das Agens der Infektion nicht mehr nachgewiesen werden kann. Bei chronischen Entzündungen z. B. findet hier und da Epithel- und Endothelwucherung statt, deren Bild im mikroskopischen Sehfeld grosse Aehnlichkeit mit echten Tumoren bietet. In diesem Fall fehlt es jedoch an Metastasen in den 
184 F. Sanfelice, Ueber die Wirkung der löslichen Produkte der Blastomyceten usw.

Organen und ist also eine Verwechslung mit dea Prozessen, die wir anlässlich der Impfversuche an Hunden beschrieben haben, ganz unmöglich.

Einige Proliferations-Infiltrate der Pleura, die andere Autoren als von Endothelien (alias Epithelien) herrührende Geschwülste betrachten, hält v. Hansemann bekanntlich für das Produkt einer chronischen Entzündung. Andrerseits ist jedoch nicht zu leugnen, dass gewisse Sarkomformen grosse Aehnlichkeit mit den Erzeugnissen einer chronischen Entzündung selbst spezifischer Natur zeigen.

Vor allem dient nun schon die Homogenität der in den Hundetumoren vorgefundenen, an Kern wie an Zellkörper einander völlig ähnlichen Zellelemente als hinreichend bedeutungsvolles Merkmal, um die oben beschriebenen Geschwülste von einem entzündlichen Gewebe zu differenzieren, indem letzteres die verschiedenartigsten Formen junger Bindegewebszellen, mit weissen Blutkörperchen jeglicher Art vermengt, aufweist, und abgesehen von der ausserordentlichen Disharmonie der Zellen, auch noch ein Ueberfluss an Fibrin vorbanden ist.

Das Vorkommen der Neubildungen in der Umgebung der Hauptgeschwulst im grossen Netz, wie der beim ersten Hund am oberen Teil der Leber der Oberfläche anhaftenden Platten, endlich der Neoplasien des Bindegewebes, wo es Nieren und Pankreas umgibt, erklärt sich leicht, wenn wir wissen, dass die malignen Tumoren zu Metastasen Anlass geben können, sei es durch Ausbreitung, direkte Auswanderung von einem Organ auf das andere, oder durch Aussaat, indem von der Geschwulst losgetrennte Teilchen sich anderswo einnisten. Dies kommt häufig in den serösen Räumen, beispielsweise im Unterleib, vor, wo die Zellen hin und her vagieren, bis sie, auf ein Hemmuis stossend, sitzen bleiben und zur Bildung einer anderen Geschwulst Anlass geben; oder schliesslich durch Wegspülen der neoplastischen Zellen und Weiterführen auf den Blut- und Lymphgängen.

In vorliegendem Fall vollzogen sich die Metastasen also auf dem Weg der Aussaat. Wie wir gesehen, zeigen sie dieselbe Struktur wie der Haupttumor; wir könuen sogar sagen, sie präsentieren den Charakter der Originalgeschwulst in reinerer Form, was als ganz besonderes Merkmal der Metastasen bösartiger Tumoren im allgemeinen gelten kann. So siebt man häufig, wie ein plattes Carcinomepithel, mit spärlichem Verhornen, bei der Metastase zu grossen Mengen von Krebsperlen ausartet.

Hinsichtlich der Metamorphosen, die an den Serosazellen vor sich gehen und mit den am oberen Teil der Leber des ersten Hundes aufgetretenen Neoplasien in Verbindung stehen, wissen wir, dass in manchen entzündlichen Wucherungen, sowie in vielen Neubildungsprozessen der Endothelien die letzteren Elemente sich in kubische und zylindrische Zellen verwandeln kömen. Bor'st sah in multiplen Bauchfellgeschwülsten das 
Endothel, welches die Oberflächenfalten der Peritonealserosa bekleidet, in kubische Elemente umgewandelt, sodass zahlreiche kleine und grosse Cystenformationen mit kolloidalem Inhalt und teils aus kubischen, teils platten Zellen bestehender Bekleidung entstanden. Auch v. Hansemann beobachtete einen vom Peritoneum aus durch Metastase an der Pleura entwickelten Tumor, dessen Elemente sich um die Gekröse-Fettzellen gruppierten und diese, kleine Cysten bildend, überkleideten; an letzteren selbst bedeckte das Epithel statt der Innen- die Aussenseite.

Bei diesen Geschwülsten ist auch das Entstehen drüsenähnlicher Neubildungen nicht ausgeschlossen, wie sie am zweiten Hund im Eettzellengewebe des Netzes, mit kubisch-zylindrischer Bekleidung, zum Vorschein kamen. In den erwähnten Metamorphosen der Deckzellen von Serosahöhlen erkannte Ribbert ganz richtig eine Rückkehr zu den Formen, welche jene in der embryonalen Entwickelungsphase besassen und sah darin einen Beweis für den epithelialen Ursprung der Endothelien.

Wir hatten der Cystenbildung in den Geschwülsten der Hunde sebon früher gedacht, nun sahen wir, dass man den gleichen Formationen auch in Bauchhöhlentumoren des Menschen begegnet ist.

Die Annahme, dass man die an den Hunden erzeugten Krankheitserscheinungen auf gleiche Weise zu erklären habe, wie solche, die beim Einführen beliebiger fremder Körper in den tierischen Unterleib herrühren, ist absolut unzulässig. Denn wenn es sich wirklich so verhielte, so hätten wir das Auftreten gleicher Neubildungen auch an den blos mit sterilisirter Nährsubstanz, ohne parasitäre Vegetation, in die Bauchhöhle geimpften Versuchstieren sehen müssen; wie schon früher hervorgehoben wurde, war dies nicht der Fall. Fremde Körper können sich, so gut wie echte Tuberkeln, in einen Mantel aus haufenweis mit Riesenzellen versebenem Granulationsgewebe hüllen. Ebenso kommt die Bildung von Riesenzellen rings um die Amyloidsubstanz und um Kankroidperlen vor, wie auch bei Echinococcus multilocularis und im Granulationsgewebe des Chalazium. Im Gegensatz dazu traten in den Geschwüren der Hunde, wie wir oben gesehen haben, die Riesenzellen nur ausnahmsweise und in minimaler Anzahl auf; und noch dazu nicht die vom Typas Langhans, deren Nukleus an der Peripherie sitzt, sondern mit eng im Mittelpunkt des Protoplasmakörpers zusammengedrängten Zellkernen.

Was vollends jeden Zweifel über die Natur der an den Hunden wahrgenommenen Veränderungen aus dem Feld schlägt, ist die Tatsache, dass in den Lymphdrüsen, in Niere, Leber und Lunge Zellnenbildungen vom gleichen Charakter wie an der Hauptgeschwulst auftraten. Da nur lösliche Produkte geimpft wurden, können diese jungen Gebilde nur von Zellelementen herrühren, die, von primitiven Tumoren ausgewandert, auf 
186 F. Sanfelice, Ueber die Wirkung der löslichen Produkte der Blastomyceten usw.

dem Wege der Lymph- und Blutzirkulation den Organen zugeführt wurden. Man hat diese Neubildungen somit als echte Metastasen zu betrachten.

Der Grundcharakter des den malignen Tumoren eigentümlichen Zellbaus, der seine Elemente vor allen anderen pathologischen und normalen Zellen des Organismus auszeichnet, besteht darin, dass sie, zwischen das gesunde Gewebe einsickernd, Veranlassung zu Metastasen geben. Die normalen Zellen des. Organismus können, an bestimmten Orten lebend, zu bestimmten Geweben in Beziehung stehen. Beinhautteilchen, die man in die Lungen einführt, leben kurze Zeit und werden hierauf resorbiert. Bringt man Gewebe verschiedener Art in die vordere Augenkammer eines Tieres, so vaskularisiren sie anfangs, um sodaun abzusterben. Sämtliche Experimente, embryonale Gewebe zu verpflanzen, führten in kurzer Zeit zu deren Resorption.

Statt dessen besitzen die Zellen der malignen Tumoren die Eigenschaft, sich fast allerorts und in den verschiedensten Organen zu entwickeln. Machen sie sich vom Muttergewebe frei, und werden durch den Lymph- und Blutumlauf anderen Organen zugeführt, so vermehren sie sich daselbst und legen nach dem angestammten Bauplan den Grund zu einer mit der Hauptgeschwulst identisch übereinstimmenden Neubildung. Diese Zellen bösartiger Geschwülste haben an Differentiation etwas eingebüsst und dafür das Vermögen individueller Existenz erworben. v. Hansemann hat den Vorgang als Anaplasie bezeichnet. Qualifiziert man eine Zelle als anaplastisch, so will dies soviel sagen, als sie sei weniger differenziert als die Mutterzelle und besitze zum Ersatz in höherem Grade die Fähigkeit für sich zu leben. Aus welchem Grunde aber vermindert sich die Differentiation und nimmt die Individualisierung zu? Die Erklärung bleibt uns v. Hansemann schuldig. Die Theorie der Anaplasie ist eine histogenetische, keine ätiologischeTheorie. Die Lehre von den Krankheitsursachen hat mit der Histogenesis nichts zu schaffen, denn die Infektion, das ätiologische Moment, geht der patbologischen Veränderung des Gewebes voran. Angesichts des ganzen weitschichtigen Problems der Genesis der bösartigen Geschwülste, ist das Feld der mikroskopischen Untersuchung ron sehr engen Grenzen umzogen. Die Arbeiten Thierschs, Waldeyers, Hausers, Borrmanns, die sich mit der Histogenesis einiger Tumoren beschäftigen, sind von höchster Wichtigkeit; zur Lösung der ätiologischen Frage tragen sie jedoch nicht bei.

Auch die Ribbertsche Theorie bewegt sich auf histogenetischem Boden und macht gleichzeitig Anspruch auf ätiologische Wichtigkeit, doch auch sie klärt uns über die Genesis der malignen Tumoren durchaus nicht auf. Nach Ribberts Ansicht wird das Carcinom von entzündlicher Proliferation verursacht; es findet dabei Ausscheidang von Epithelzellen statt und diese bringen die Geschwulst zustande. Bei wie manchem Entzündungs- 
prozess scheiden nicht Deckzellen aus, und doch gibt es keine Geschwulst! Das sind also wohl Entzündungen von ganz speziellem Verlauf; die zum Entstehen von Tumoren Hand bieten; welches ist nun die Ursache dieses Prozesses? Welche Menge von Geschwälsten treten nicht ohne die mindeste Spur von Entzündung auf! Und wie viele Neubildungen sieht man nicht - wie v. Hansemann selbst versichert -, bei denen es ganz ohne anaplastische Modifikationen abläuft, trotzdem die Geschwülste nach klinischem Begriff zu den malignen zählen!

Solche Ausnahmen dienen nur dazu, Skeptizismus zu erzeugen, selbst da, wo die Theorie von Onkologen von Bedeutung aufgestellt wurde. Bevor von histologischen Veränderungen die Rede sein kann, muss das chemische Reizmittel in Aktion treten, da von ihm das Wuchern der Zellelemente abhängt. Das Herbeischaffen dieses Reizes ist aber, wie in allen anderen infektiösen pathologischen Prozessen, lediglich Aufgabe der Mikroorganismen.

Nun geht aus den bisher mitgeteilten Experimenten bervor, dass den Blastomyceten die Fähigkeit innewohnt, sowohl in Kulturen als im Organismus Substanzen auszubilden, deren Leistung im Anreizen der Zellelemente zur Proliferation besteht; von den so entstandenen echten Neoplasien lösen sich hierauf Zellen aus, die, den Stimulus mit sich führend, das Werk der Vermehrung in den Lymphdrüsen, der Leber, der Lunge fortsetzen.

Wird auf Grund dieser Ergebnisse den Sprosshefen die Eigenschaft zuerkannt, mittelst ihrer Produkte die Zellen zur Neubildung anzustacheln, so kommen wir notgedrungen zu dem Schluss, dass die einmal in ihrem Biochemismus modifizierte Zelle sich vermehrt und sich zu vermehren fortfährt, bis es ihr gelungen ist, sich des störenden Produktes, Form und Funktion alterierend, zu entledigen (Anaplasie).

Der ätiologische Faktor maligner Tumoren - als solchen haben wir die auf den Schleimhäuten oder auf der Kutis, ausnahmsweise auch im Inneren des Organismus hausenden pathogenen Sprosshefen zu betrachten tritt mit dem Augenblick in Aktion, wo die erlahmende Zellresistenz ihm gestattet, sich zu vermehren und hierauf die, zur atypischen Wucherung anreizende, Wirksamkeit seiner Produkte einzuleiten. Im weiteren Verlauf übernimmt sodann die gereizte Zelle die Urheberschaft der Neoplasie. Für die Tatsache, dass die Zellen der bösartigen Tumoren irgend eine anf die Organismuszellen aIs Stimulus zur Neubildung wirkende Substanz einschliessen, lieferten die schon früher zitierten bedeutungsvollen Experimente Lewins den besten Beweis. Die Metastasen, die dieser Forscher in der Leber und der Lunge von Hunden durch Peritonealimpfungen mit Ovariumkrebszellen zustande gebracht hat, zeigen, wie aus den die Arbeit begleitenden Figuren zu ersehen, grosse Aehnlichkeit mit denjenigen, welche die löslichen Produkte der Sprosspilze erzeugten. Geht man von der Vor- 
188 F. Sanfelice, Ueber die Wirkung derlöslichen Produkte der Blastomyceten usw.

stellung aus, die Zelle erlange durch den empfangenen Reiz eine bostimmte Reproduktions-Potenzialitä, die an der Reizstelle oder selbst auf Distanz zum Ausdruck gelangt, so bedarf die hier und da gelungene Lebertragung der Tumoren von Tier zu Tier der gleichen Spezies keiner weiteren Erklärung. Allerdings eignet sich dann, auch dies ist begreiflich, nicht jede Art von Geschwülsten zum guten Ausgang dieser Experimente, soudern nur solche, deren Zellen im Uebersiedelungsmoment sich im Besitze reproduktiver Potenzialität befinden, mit anderen Worten: die Gegenwart eines gewissen Vorrats von Produkten, deren sie sich noch nicht entledigen konnten, spielt bei dem Vorgang eine Rolle.

Es liesse sich einwenden, die Neubildungen der Lymphdrüsen, der Leber, Niere und Lunge von Hunden infolge von Abdominal-Impfung mit löslichen Produkten, denen ich die Bedeutung von Metastasen gab, seien nicht sowohl dies, als vielmehr Veränderungen entzündlicher Natur, hervorgebracht durch die vom Parasiten in vitro bereiteten und in den Blutkreislauf übergegangenen Substanzen. Doch kam ich einer solchen Auffassung keinen Wert beilegen, vor allem darum nicht, weil die an den Organen auftretenden Neubildungen ein mit dem der Hauptgeschwulst übereinstimmendes Zellgefüge aufweisen, wie beispielsweise die Cystenformationen (Tafel II, Fig. 3), die man weder in normalen, noch in den von infektiösem Granulom heimgesuchten Lymphdrüsen antrifft. Für das Entstehen dieser Neubildungen gibt es daher nur eine Auslegung: die Vermehrung der vom Haupttumor losgetrennten und auf die Organe übergegangenen Zellen. In zweiter Linie müssten diese Veränderungen, will man sie den im Kreislauf vorgedrungenen löslichen Produkten zuschreiben, eine weit, weit grössere Verbreitung gewonnen haben. Tatsächlich konzentrierte sich die ansehnlichste der Erscheinungen im grossen Netz, mit sekundärer Knötchendiffusion in der Umgegend; erst darauf erfolgten Neubildungen in den Organen. Der Krankheitsverlauf ging somit etappenweise vor sich, ganz wie in den malignen Tumoren. Drittens handelt es sich nicht um eingebrachte Mikroorganismen, da nicht diese, sondern ausschliesslich Nährbodensubstanz mit den darin verteilten löslichen Produkten der Parasiten zum Impfen dienten; diese Produkte setzen sich im Netz fest und gaben Veranlassung zu der Hauptgeschwulst; sicher sind nicht die Nährbodenpartikel nach den Organen ausgewandert, wo man sie mit Leichtigkeit gefunden hätte, sondern nur die von den hauptsächlichsten Neubildungen abgelösten Zellen.

Es gibt nur zwei Auswege: entweder weist man diese pathologischen Prozesse der experimentellen Onkologie za, oder man schiebt ein neues Kapitel pathologischer Anatomie ein, wo sie ein Plätzchen finden. Die auatomischen Pathologen haben das letzte Wort zu sagen. 
Lassen wir, auf die gemachten Experimente gestützt, das Faktum gelten, dass die Parasiten und ihre Produkte in einer ersten Periode auf die Zellen einen Reiz zur Vermehrung ausüben und die Entwickelung der Geschwulst nur eine Folge ihrer morbösen Sprossenwucherung ist, so haben wir die Erklärung für das seltene Auftreten der Pilze in den Geschwülsten, namentlich in lang andauernden, andererseits aucb diejenige für ihre eventuelles Fehlen in den Metastasen.

Von der anatomischen Phase, die rapide und ausgiebige Vermehrung der Parasiten bei karger Reaktion seitens der Organismuszellen (diffuse Blastomykose) kennzeichnet, geht der Krankheitsprozess zu der pathologischen Phase über, wo die Hefen höchst spärlich oder ganz und garnicht auftreten (experimentelle Intoxikation) und die Gewebsreaktion bloss als Resultat der Einwirkung von löslichen Produkten zu betrachten ist. Das Bild der infektiösen und Intoxikationsaktion der Blastomyceten tritt damit in den Rahmen der allgemeinen Gesetze zurück, welche die pathogene Wirksamkeit aller bis jetzt bekannten Mikroorganismen regelt.

Es ist hier nötig, von der Klassifizierung der am Hund beobachteten Unterleibsgeschwülste zu sprechen.

Die Deckzellen der serösen Räume betrachten viele als endotheliale, andere dagegen als epitheliale Zellen. Marchand und Benda sind letzterer Ansicht und betrachten daher die Geschwülste, die aus Bekleidungselementen der Serosa entstehen, als Carcinome. Borst bingegen zählt zu den Vertretern der ersteren Auffassung. Soviel ist gewiss, dass die Endothelien eine Zwitterstellung zwischen Epithelium und Bindegewebszellen einnehmen, indem bei ihnen, die Verhältnisse mögen normal oder pathologisch sein, eine ausserordentliche Mannigfaltigkeit zum Vorschein kommt. Aus diesem Grund gelten die Endotheliome bei vielen für Epithel-, bei anderen für Bindegewebsgeschwülste. Ribbert hält ganz logisch an der Enterscheidung zwischen Epithelium und Endothelium fest. Von morphologischen Kriterien ausgehend, charakterisiert er als Endothelium eine dünne, bloss einschichtige, aus platten Zellen bestehende Membran und zählt dazu die Deckzellen der serösen Höhlen, der Blut- und Lymphgefässe und.der Bindegewebsspalten.

Die Tumoren, die wir an den Hunden wahrgenommen haben, können sich ebensogut aus den Bekleidungszellen der Serosa als aus denen der Lymphspalten im grossen Netz gebildet haben; im einen wie im anderen Fall sind sie den Eudothelien einzureihen.

Verschiedene Autoren bezeichnen das Endotheliom der serösen Räume mit dem Namen Endothelialkrebs, indem sie es seiner ausgedehnten Verbreitung und speziellen Entwickelungsart halber von den übrigen Endotheliomen differenzieren. Wagner, Schulz und Thierfelder haben solche Tumoren beschrieben. Es handelt sich in diesem Fall um einen 
mehr oder weniger über die ganze Oberfläche einer serösen Höhle ausgedehnten Neubildungsprozess, der weissliche Verdickungen, granulöse und Knötchenwucherungen bis zur Bildung grosser knorriger Massen, hervorbringt, wie wir es an den Versuchstieren gesehen haben. Das Gebiet, wo all diese jungen Formationen auftreten, beschränkt sich auf die Serosa. In das von ilir umhülite Parenchym der Organe dringen sie, wie es sich bei den am Oberteil der Leber des ersten Hundes aufliegenden Platten zeigte, nicht ein. Metastasen gehören gar nicht zu den Seltenheiten. Glockner fand sie in den Lymphdrüsen verschiedener Regionen, so in Leber, Niere, Perikardium, im Muskelsystem, in den Nebennieren, im Nierenbecken und in der Vesica. Den Neubildungsprozess begleitet in der Regel chronische Entzündung mit Fibrinabsonderung, die zu mannigfachen Adhärenzen zwischen den Organen führt.

Bei den Endothelgeschwïlsten der Serosakavitäten sind die Abweichungen vom platten Zellentypus des Endothels eine bäufige Erscheinung, so treten grosse polymorphe, Epithelzellen ähnelnde Elemente mit Bläschenkern und reich an körnigem Protoplasma auf, ferner zylindrische Formen und mehr oder weniger ansehnliche Gruppen epithelioider Zellen.

Als Beispiel eines Endothelioms der Serosahöhlen des Menschen fübre ich ein ron Borst beobachtetes Beispiel an, da zwischen diesem und den bei Hunden auftretenden Veränderungen auffallende Analogie herrscht. Es handelte sich um eine auf die ganze Peritoneumserosa ansgedebnte Neoplasie. Am Bauchfell erschien die Geschwulst in Gestalt grosser und kleiner Knoten, zusammenfliessender Plättchen und Papillenwucherung; in das Parenchym der Unterleibsorgane drang sie nicht ein. Die Serosa war an der ganzen Oberfläche mit Cysten verschiedener Grösse, mit kleisterartigem oder muco-serösem Inbalt, besät. Besonders die Rectouterin- und Vesicunterinhöhlen waren voll solcher Cysten. Netz und Gekröse war geradezu in eine neoplastische Masse mit vielen solcher Formen umgestaltet. Adhärenzen entzündlichen Ursprungs traten in grosser Zabl auf. Die Neubildungen am Diaphragma besetzten in Gestalt zahlreicher Knötchen die Unterseite. Auch die Lymphdrüsen der Retroserosa und des Ileum waren von Vetastasen befallen. Die Cysten waren aus einer Schicht kubischer Zellen aufgebaut and verdankten das Entstehen ihres kolloiden oder schleimigen Inbalts einem Sekretionsprozess der Deckzellen. Die Geschwulst, die auch die Lymphgefässe der Serosa ergriffen batte, zeigte bald Alveolenstruktur mit polymorphen Zellen, bald netzartige Anordnung, so in einem Eudotheliom der Lymphspalten. Die grösstenteils epithelähnlichen Zellen, protoplasmareich mit grobem Zellkern, bildeten hier uud da Synzytialmassen. Anderswo entwickelten sich an den grösseren: Lymphgefässen Mandelformationen aus kubischen und zylindrischen Zellelementen. Hier brachten polygonische Zelien ohne Interstitiumsubstanz, wie in den Alveolen 
eines Carcinoms, ein Mosaik zum Vorschein, dort vereinigten sie sich, abgeplattet, z! geschichteten Lagern.

Sehen wir nun, was im Verlauf chronischer Entzündungen mit den Endotheliumzellen vorgeht. Marchand sah bei derlei Prozessen das Endothel des Bauchfells zu grossen Kugelzellen ausarten und beträchtliche Konglomerate angeschwollener Elemente entstehen, in welchen durch Konfluenz der Vakuolen sich leere Räume bildeten. In Fällen andauernder Entzündung der Serosahöhlen sah Borst das Auftreten granulöser Wucherung polymorpher Zellen, häufig mit mehreren Kernen von konzentrischer Zellschichtung. Auch Hamerl, Graser und andere mehr machten die Wahrnehmung, dass bei chronischen Entzündungen die Endothelzellen an der Bildung des Granulationsgewebes teilnehmen. Bei den spezifischen Entzündungen, besonders tuberkulöser Natur, gestalten sich die Endothelzellen in epithelioide und Riesenzellen um.. Cornil und Chaput sahen bei experimentellen Entzündungen der Serosaräume und bei der Organisation der einfachen. Hämorrhagien aus Endothelien grosse, mit Verlängerungen ausgerüstete Zellelemente hervorgehen. Ranvier und Paltauf bemerkten, dass die Endothelien der Serosahöhlen die Fähigkeit besitzen, Interzellularsubstanz zu bilden.

In betracht der mannigfaltigen Gestalt, welche die Endothelzellen der Serosaräume bei chronischer Entzündung annehmen können, und welcher eine gewisse Aehnlichkeit mit den bei Neoplasie auftretenden Erscheinungen nicht abzusprechen ist, lässt es sich leicht erklären, wenn hier und da in einem besonderen Fall die differenzierende Diagnose, selbst für gewiegte pathologische Anatomen, ihre. Schwierigkeit haben kann. Die für charakteristisch geltenden Eigenschaften der Endotheliome, d. h. die schleimige, hyaline und amyloide Degeneration und das Vorkommen geschichteter Zellenbildung reichen an Bedeutung bei weitem nicht an die der Gegenwart von Metastasen.

V.

Ich gehe zur Beschreïbung der Impferfolge an Katzen über, die man durch Einführen der Produkte allein oder mit den Parasiten vereint, erzielte.

Es fauden im ganzen 16 Versuche an diesem Versuchstier statt. Die beiden ersten geschahen mit Injektion der Produkte allein in die Bauchhöhle, drei andere gleichen Orts mit Parasiten und Produkten. Bei weiteren drei Experimenten kam endovenöse, und bei den acht letzten tracheale Einspritzung von Parasiten und Produkten in Anwendung.

Zur Unterleibsimpfung der ersten Katze dienten die löslichen Produkte einer Kultur von Saccharomyces canis II auf Kartoffel, in zugeschmolzenem Röhrchen anderthalb Monate im Warmschrank gebalten. Das 
192 F. Sanfelice, Ueber die Wirkung der löslichen Produkte der Blastomyceten usw.

Tier starb nach 38 Tagen. Sektionsbefund: Im grossen Netz erbsen- bis bohnengrosse Knötchen; Milz etwas angeschwollen; Leber an der Oberfläche mit teilweise über die Oberfläche vorragenden Neubildungen besetzt, den am ersten Hund konstatierten durchaus ähnlich; Mesenteriallymphdrüsen stark angeschwollen; Lungenregion: die Pleuraunterseite mit Knötchen besetzt.

Histologisch zeigen die Knötchen im Netz das gleiche Strukturbild wie die Abdominalgeschwülste der Hunde, mit dem Unterschied, dass die Cystenformationen viel seltener auftreten und nicht aus mehrfach geschichteten, sondern nur einer Lage zylindrischer Zellen bestehen. Die an der Leberoberfläche aufsitzenden Plättchen sind dafür um so ausgiebiger mit Cysten aus mehrschichtigen Zylinderzellen versehen. Im Leberparenchym fehlt es an Metastasen. Die Niere bietet nichts Bemerkenswertes. An den Unterleibs-Lymphdrüsen fanden sich, namentlich an der Peripherie unter der Kapsel, Flecke von jungem Gewebe, ähnlich dem der in der Unterleibshöhle vorkommenden Knötchen (Tafel II, Fig. 8). An Milz und Pankreas keine Veränderungen. Die subpleuralen Knötchen der Lunge bestanden aus dem gleichen Gewebe wie die Neubildungen der Bauchhöhle und der Lymphdrüsen.

Der zweiten Katze wurden gleichfalls im Unterleib dis Produkte einer auf Kartoffeln gezüchteten und in geschlossenem Röhrchen 3 Monate lang im Thermostaten gehaltenen Kultur von Saccharomyces canis II beigebracht. Das Tier erlag nach 41 Tagen. Die Sektion ergab: Neubildungsmassen im grossen Netz und im Mesenterium mit Adhärenz an die Bauchwandung; Unterleibslymphdrüsen waren stark angeschwollen: keinerlei Affektion von Leber, Milz und Nieren; an den Lungenflügeln die subpleuralen Knötchen; die Bauchserosa wies keine entzündliche Reaktion auf. Kultursaaten aus den Unterleibsorganen blieben steril.

Der histologische Aufbau der Hauptgeschwulst ist eine ganz identische Wiederholung von dem, was an der ersten Katze zum Vorschein kam. Es macht sich eine reichliche Infiltration seitens der neugebildeten Elemente des Fettzellgewebes geltend, das die Hauptmassen der im Unterleib aufgetretenen Neoplasien umgibt. Im Leberparenchym zeigen sich viele kleine Flecke von dem Hauptumor ähnlichem Gewebe. Auch an der Niere kommen, sowohl in der Rinden- als in der Marksubstanz, kleine Neubildungen zum Vorschein. Die Metastasen in den Lymphdrüsen sind von grösserer Ausdehnung als bei der vorigen Katze. An mehreren Mandeln ist die ganze Rindensubstanz von neugebildetem Gewebe in Besitz genommen. Auch im Pankreas zeigen sich kleine Metastasen. Die Follikel des Dünndarms sind mächtig angeschwollen, weisen aber keine jungen Zellen auf. An der Milz ist nichts zu sehen. Ausser den Knötchen der Pleura treten 
in der Lungenregion noch andere auf, die zu den kleinen Bronchien, den Arterien und Venen in Beziehung stehen.

Gesamtbild: Das Einführen der Produkte pathogener Sprosshefen in die Abdominalhöhle batte Neubildungen des Bindegewebes und Metastasen in den Organen hervorgerufen, die durchaus mit den an Hunden gemachten Beobachtungen übereinstimmen.

Resultate der zweiten Serie von Impfversuchen mit Produkten und Parasiten am Unterleib von Katzen. Der ersten, infizierter Impfstoff: eine Kultur auf Kartoffel von Saccharomyces canis 6 Monate bei Zimmertemperatur aufbewahrt. Das Tier starb nach 50 Tagen; bei der Sektion kam in der Bauchhöhle ein Tumor zum Vorschein (Tafel I, Fig. 4), der sich $8 \mathrm{~cm}$ lang, $4 \mathrm{~cm}$ breit und im Mittel $1 \frac{1}{2} \mathrm{~cm}$ dick von der Leber bis zur Blase ausdehnte. Mit der Milz hing die Geschwulst so innig zusammen, dass das Organ förmlich darin aufging. Bei der Leber war dies nur teilweise der Fall; ihre untere Partie war grösstenteils frei, nur eine eng umgrenzte Stelle hing mit der Bauchwand zusammen. Der Tumor zeigte eine gelblichweisse Farbe und die Konsistenz von Fischfleisch. Diese neugebildete Masse rührte unzweifelhaft vom grossen Netz her. Die Abdominallymphdrüsen waren stark geschwollen; die Leber von zablreichen, sowohl oberflächlichen als tiefergehenden Metastasen heimgesucht; die Milz bewahrte ihr normales Volumen. An der Niere nichts wahrzunehmen, die Lunge dagegen enthielt metastatische Knoter.

Die Zellen, aus welchen der Haupttumor besteht, bilden, mit Bläschenkern und reichlichem Protoplasma ausgerüstet, mehr oder weniger grosse, durch Bindegewebsfasern getrennte Schollen (Tafel II, Fig. 5). An verschiedenen Stellen der Geschwulst treten in ansehnlicher Menge die geschichteten konzentrischen Kugeln auf, die man im Epithelialkrebs zu sehen bekommt.

Eine ganz ähnliche konzentrische Ordnung der Geschwulstzellen umgibt auch einige kleine Zellnester sowie ganz winzige Gefässe. Ueber den Tumoren verstreut bemerkt man stellenweis myxomatöse Degeneration. Wo die Serosa einen Punkt der Geschwulstoberfläche berührt, zeigt das Epithel kubische Zellen. In der Leber kommen Metastasen verschiedener Grösse zum Vorschein. Die kleinsten füllen die. Kapillareu in solcher Menge aus, dass sich deren Wände ausdehnen; an den grösseren kommt keine Regelmässigkeit der Form vor. Selbst in den bedeutendsten Metastasen im Leberparenchym ist die Neigung der Zellelemente, konzentrische Kugelform anzunehmen, ganz ausgesprochen. Rinden- und Marksubstanz der Niere sind von Metastasen befallen. In der Milz lagern die neugebildeten Zellen, wie es den Anschein hat, in Reihenordnung zwischen den Maschen des Gewebes. Dasselbe Organ weist auch da und dort Riesenzellen auf, deren verschweisste Kerne dicht am Zentrum des Proto- 
194 F. San felice, Ueber die Wirkung der löslichen Produkte der Blastomyceten usw.

plasmakörpers liegen. Die zahlreichen Metastasen der Unterleibslymphdrüsen präsentieren sich entweder als Flecke im Rindenteil oder (in den Schnitten) halbmondförmig unterhalb der Kapsel. Im Mittelteil der Mandeln ersetzt das neugebildete Zellgewebe die Lymphstränge des Marks. An den Wänden mancher Dünndarmzotten finden sich der Hauptgeschwulst ähnliche Neoplasien. Die Lymphfollikel des gleichen Darms sind beträchtlich angeschwollen und weisen Flecke neuer Zellenbildung auf. Im Mark der langen Knochen gibt es keine Metastase. In der Lunge findet man sie unter der Pleura und selbst tief im Innern des Organs, von wechseluder Ausdehnung und stets gleicher Struktur. In der Gegend, wo solche Metastasen auftreten, wuchert hier und da das Bronchienepithel unter Abweichung vom morphologischen Normaltypus, indem die Proliferation aus zahlreichen Falten mit Auskleidung zylindrisch-atypischer Deckzellen besteht. Man beachte wohl, dass in der Lunge keine strongylusläsion vorkam. Von den kleinen Arterien, die sich im Bereich der Metastasen finden, oder von solchen ergriffen sind, tragen manche an der Gefässwand Usuren zur Schau, während Pfropfen neugebildeter Zellen das Innere fast vollkommen verstopfen.

Die zweite, mit Parasiten und Produkten einer wenige Tage in geschlossenem Röbrchen gehaltenen Kultur von Saccharomyces canis I geimpfte Katze starb nach 40 Tagen und wies in der Bauchhöhle eine deutlich in drei Partien abgegrenzte neoplastische Masse auf (Tafel I, Fig. 3). Der grösste vordere Teil, von Gestalt und Grösse einer kleinen Birne, haftete an der Bauchmuskelwand; oberhalb und seitwärts von derselben der zweite etwas kleinere Teil; der dritte, von gleichem Umfang wie voriger, sass rechts hinter der grossen Partie, durch einen dicken Stiel mit ihr verbunden. Die Abdominallymphdrüsen waren so stark angeschwollen, dass mehrere die Grösse einer kleinen Kastanie erreichten. An Leber, Milz und Nieren war nichts Erwähnenswertes zu entdecken. Die hinteren Lungenränder wiesen kleine gräuliche Flecke auf. Von Veränderungen durch Strongylus auch hier keine Spur.

Der histologische Bau der neoplastischen Masse im Unterleib stimmt mit dem am vorerwähnten Versuchstiere beobachteten durchaus überein. Weder an der Leber noch an der Milz traten Metastasen auf, wäbrend sie sowohl Rinden- als Marksubstanz der Lymphdrüsen affizierten; Flecke junger Zellformation umgaben und ersetzten grossenteils die Follikel. Die Lymphräume der Marksubstanz einiger Mandeln steckten geradezu voll neugebildeter Zellen. Milz frei von Metastasen. Was die Lunge betrifft, ahmten die Neoplasien an der inneren Brustfellseite im Bau die Hanptgeschwulst nach; im Parenchym und in der Nähe kleiner Bronchien und Blutgefässe hatten sich dagegen lileine Metastasenknötchen eingenistet. Die dritte Katze, der man Parasiten und Produkte einer Kultur von 
Saccharomyces can is I in die Bauchböhle eingeführt hatte, starb nach 46 Tagen, doch fiel der Sektionsbefund hier durchaus negativ aus.

Der Trachealinjektion mit Parasiten und Produkten aus alten Kulturen pathogener Sprosshefen erlagen die Katzen nach 18 bzw. 21, 41, 48, 56 , 67, 88, 114. Tagen; die anatomisch-pathologischen und histologischen Sektionsbefunde waren stets die gleichen. Die oft nur auf einen Lungenfügel beschränkte, anderswo auf mehrere ausgedehnte Veränderung dieses Organs erschien in Gestalt von Hepatisation mit gelblichweisser Farbe. Betrachtet man den angegriffenen Flügel, so sticht an der Oberfläche vor allem ein im Aussehen von der normalen Lunge gänzlich verschiedener Fleck mit gewellten Rändern hervor. Beim Durcbscbneiden des Stückes erschien an dieser Stelle die kompakte Masse des neugebildeten Gewebes von demjenigen des normalen Organs scharf abgetrennt und von so zarter Konsistenz, dass mit der Messerschneide sich leicht eine kleine Portion abheben liess. Wie schon erwähnt, bestanden bei einigen Katzen ganze Lungenflügel aus neugebildetem Gewebe, während bei anderen nur eng umgrenzte Teile mit.Neoplasie behaftet waren.

Sonst begegnete man in den Organen dieser infolge endotrachealer Impfung gestorbenen Tiere in der Regel keinen Veränderungen. Nur bei der nach 114 Tagen verendeten Katze VIII erschien die Rindensubstanz des Tieres mit Knötchen besetzt.

Die Gewebszellen der jungen Formation sind grösstenteils mit intensiv gefärbten Bläschenkernen und ansehnlichem Protoplasma ausgerüstet, das sich manchmal von dem der umliegenden Zellkörper sehr gut unterscheiden lässt, oft auch mit ihrem Protoplasmainhalt verschmilzt. Hier und da begegnet man in diesem neugebildeten Gewebe mehr oder weniger reichlicher Leukozyteninfiltration; auch fehlt es unter den Zellkörpern nicht an Degenerationsphasen in Gestalt bald mehr, bald weniger ausgedehnter hyaliner Flecke. Das Auftreten normaler wie pathologischer karyokinetischer Figuren ist keine Seltenheit.

Am Gerüst des neugebildeten Gewebes nehmen auch die Alveolarzellen teil, indem sie die wenigen Alveolarräume, die nicht von den obenbeschriebenen jungen Zellen in Beschlag genommen waren, dichtgedrängt ausfüllen. Ihr Protoplasma ist ausgiebig mit hyalinen Flecken versehen. Diese Gruppen von Alveolarzellen zeigen leichte Leukozyteninfiltration. Als weiteren Bestandteil des jungen Gewebes sehen wir die Proliferation des Bronchialepithels in Form eines reichen ein- und ausgebuchteten Faltenwurfs. Die Hauptrolle beim Aufbau des neugebildeten Gewebes spielen Zellen endothelialen Ursprung;s; denn sowohl die Wucherungen des Bronchialepithels als die Alveolarzellen sind tatsächlich als Kundgebung einer Reaktion zu betrachten. 
196 F. Sanfelice, Ueber die Wirkung derlöslichen Produkte der Blastomyceten usw.

Wir wissen, dass njcht nur bei alsuten, sondern auch bei chronischen Entzündungen dic Endothelzellen der serösen Membran, der Blut- and Lymphgefässe und der lymphatischen Spalten sich bei der Bildung des Granulationsgewebes beteiligen. Alle Metamorphosen, die während der verschiedenen. Phasen des Entzündungsprozesses an diesen Zellen vor sich gehen, treten auch in den, ursprünglich von ihnen herrührenden, Geschwülsten auf. Wir finden daher im Endotheliom dieselbe Mannigfaltigkeit von Zellformen, der wir im Verlauf der Entzündung begegnen. Nun kann man aus Gründen, die schon hinsichtlich der in Unterleib der Hunde zutage getretenen Veränderungen erörtert wurden, die in der Katzenlunge auftretenden Absonderlichkeiten nur als neoplastisches Erzeugnis und keinenfalls als Erscheinung entzündlicher Natur auffassen. Dazu kommt noch, dass in der Rindensubstanz der Niere einer Katze Knoten von gleichem Gefüge vorkamen, wie das neugebildete Gewebe der Lunge sie aufwies.

Es bleibt mir, um mit der Experimentenserie an Katzen abzuschliessen, nur noch die Berichterstattung über das Ergebnis der endovenösen Injektion von Parasiten mit Produkten übrig. Drei Katzen wurden Kulturen von Saccharomyces canis II eingebracht.

Das erste der Versuchstiere starb nach 24. Tagen mit Veränderungen an Leber und lunge. Auf ersterer zeigten sich kleine, gelbliche, linsengrosse Flecke; die Lungenoberfläche war durchweg mit Knötchen übersät. Diese Veränderungen erschienen histologisch identisch mit denen, die in gleicher Weise behandelte Hunde aufwiesen.

Die zweite Katze starb nach 38 Tagen. Es zeigte sich Anschwellung der subkutanen Drüsen der Achselhöhle und Leisten, der Unterleibslymphdrüsen, eine Milzgeschwulst mit zerklüfteter Oberfäche, Nierenschädigung in Gestalt stecknadelkopfgrosser Knötchen in der Rindensubstanz, endlich die gleiche Erscheinung an Leber und Lunge.

Besonders hervorragende Ergebnisse waren bei diesem Versuchstier der histologischen Untersuchung der subkutanen and abdominalen.Lymphdrüsen und des Knochenmarks vorbehalten: In den Lymphdrüsen bekam man rings um die Follikel neugebildete Zellfiecke zu sehen und ganz dieselben Elemente füllten in einigen Mandeln auch die Lymphspalten der Marksubstanz aus. Ebenso liamen im Mark der Röhrenknochen mit den in den Lymphdrüsen gesehenen identische Zellflecke zum Vorschein. Die Veränderungen an Leber, Niere und Lunge stimmten durchaus mit dem überein, was die Versuche an Hunden aufgewiesen hatten.

Die dritte Katze starb nach 55 Tagen. Die Infektionserscheinungen beschränkten sich auf Nieren, Lunge und Gehirn. Die Veränderungen an Niere und Lunge unterschieden sich in nichts von den oben beschriebenen. Ueber die Oberfläche des grossen wie des kleinen Hirns ragten erbsen- 
grosse Neubildungen hervor, die übrigens, wie die Schnitte zeigten, auch im Inneren sowohl der grauen als der weissen Substanz nicht fehlten.

Histologisch bestanden diese Neoplasien aus den gleichen Zellelementen wie die der übrigen Organe.

Somit hringt endovenöses Impfen der mit Parasiten vereinten Produkte auf Katzen ganz die gleiche Wirkung hervor wie auf Hunde. Auch von Natur sind die zutage tretenden Erscheinungen die gleichen.

Die Zahl positiver Resultate, welche das Einführen von Produkten allein oder dieser mit dem Parasiten vereint an Katzen hervorgebracht hat, übersteigt alle bei früheren. Impfversuchen, nur mit Parasiten erzielten Erfolge ganz bedeutend. Ausserdem waren die hervorgebrachten Krankheitserscheinungen von viel grösserem Belang und öffueten eiwem sorgfältigeren Studium und zuverlässigerer Diagnose die Bahn.

Aus der Gesamtheit der hier vorgeführten Versuche berechtigt, ziehen wir folgende Schlüsse:

1. Die Zellen des Organismus reagieren gegen die Wirkung der ]öslichen Produkte der Blastomyzeten, indem sie sich unter Wandlung von Form und Funktion (Anaplasie) vermehren und lokale Bildung eines neoplastischen Gewebes veranlassen. Ausgelöste Bestandteile des letzteren können auf dem Wege der Lymph- und Blügänge șich in beliebiger Entfernung auf den Organen niederlassen und hier neues Gewebe aufbauen, identisch von Struktur mit dem Gebilde, von dem sie ausgingen.

2. Dieses Faktum bildet den Grundstein der Differentiation der malignen Tumoren von den Geschwülsten chroniscber Entzündung. Somit müssen durch Sprosshefen hervorgerufene Veränderungen der Klasse der echten Neoplasien zugeteilt werden.

\title{
Erklärung der Figuren auf Tafel I und II $^{1}$ ).
}

\author{
Tafel I.
}

Figur: 1. Präputiumsarkom eines Hundes. Entstanden durch Injektion der von einer Kultur von Saccharomyces canis II auf Kartoffel gebildeten Produkte, und in das subkutane Bindegewebe der Penisregion eingeführt. Das T'ier starb 15 Wochen nach stattgehabter Operation. Die Photographie stellt den Tumor in $1 / 3$ natürlicher Grösse dar.

Figur 2. Geschwulst in grossen Netz eines Hundes, in der Mitte durchschnitten. Der Tod des Tieres trat 15 Wochen nach empfangener Bauchhöhlenimpfung mit den Produkten einer Kultur von Saccharomyces can is II auf Kartoffel ein. Photographische Aufnahme in natürlicher Grösse.

1) Die photographischen Reproduktionen der milroskopischen Präparate verdanke ich der Zuvorkommenheit von. Dr. Buggiero Schiff. 
198 F. Sanfelice, Ueber die Wirkung đerlöslichen Produkte der Blastomyceten usw.

Figur 3. Unterleibsgeschwuist im grossen Netz einer Katze, als Folge von Impfung mit Parasiten und Produkten einer Kultur von Saccharomyces can is I auf Kartoffel. Das Tier starb 40 Tage nach der Impfung. Photographische Darstellung des Tumors in natürlicher Grösse.

Figur 4. Geschwulst im grossen Netz einer Katze. Tod erfolgt 50 Tage nach Unterieibsimpfung mit Parasiten und Produkten einer Kultur von Saccharomyces canis I auf Kartoffel. Photographie: Natürliche Grösse.

Figur 5. Leber eines 1 Monat nach empfangener Abdominalimpfung gestorbenen Hundes. Impfstoff: die löslichen Produkte aus der Kultur eines pathogenen Blastomyceten auf Kartoffel. Der Hefepilz wurde aus einem infektiösen Ovariumpapillom isoliert. Am oberen Teil der Leber kommen, über die Oberfläche zerstreut, Neubildangen zum Vorschein, die durch Ausstreuung von Teilchen der ursprünglich im grossen Netz gebildeten Geschwulst herrühren. Photographische Abbildungen der Leber in natürlicher Grösse.

Figur 6. Metastasen im Fettzellengewebe des grossen Netzes eines Hundes. Eintritt des Todes 56 Tage nach Abdominalinjection der Produkte aus einer Kultur ron Saccharomyces canis II. Oc. 2. Ob. O. Zeiss.

Figur 7. Schnitt einer Neubildung, die an der Leberoberfläche vorerwähnten Hundes aufgetreten. Cystenformation mit geschichtetem Epithel. Oc. 2. Ob. C. Zeiss.

Figur 8. Metastase in einer Retroperitoneal-Lymphdrüse eines Hundes. Tod einen Monat nach Bauchböhlenimpfung. Impfstoff: die lōslichen Produlite aus der Kultur einer von infektiöser Papillengeschwulst des Eierstocks isolierten Sprosshefe. Oc. 3. Ob. C. Zeiss.

Figur 9. Schleimhaut der Präputiumwandung eines in das sublutane Bindegewebe des Penis geimpften Hundes, der 1 Monat nach stattgefundener Infelition getötet wurde: Impfstoff: Produlite aus einer Kultur von Sacoharomyces canis II auf Kartoffel. Photographische Aufnahme der Mukosa in natürlicher Grösse.

Figur 10. Metastase an der Oberfläche der oberen Leberpartie eines Hundes. Cystenbildung mit mehrfach geschichtetem Epithel. Oc. 4. Ob. 5 . Koristka.

\section{Tafel II.}

Figur 1. Lungenneoplasie eines Hundes. Tod des Tieres erfolgt 1 Monat nach der Injektion löslicher Produkte in die Bauchhöhle aus der Kultur einer im infektiösen Papillom isolierten pathogenen Sprosshefe. Oc. 4. Ob. 5 . Koristlia.

Figur 2. Metastase im Fettzellgewebe des grossen Netzes eines 56 Tage nach der Abdominalimpfung gestorbenen Hundes. Impfstoff: Produkt aus einer Kultur yon Saccharomyces canis II auf Kartoffel. Oc. 4. Ob. 5. Koristka.

Figur: 3. Metastase in den retroperitonealen Lymphdrüsen eines Hundes. Tod erfolgte 15 . Wochen nach der Einspritzung löslicher Produkte in die 
F. Sanfelice, Ueber die Wirkung derlöslichen Produkteder Blastomyceten usw. 199

Bauchhöhle aus der Kultur von Saccharomyces canis II. Neubildung der im Haupttumor bestehenden Gystenformation in der Drüse. Oc. 4. Ob. 5. Koristka.

Figur 4. Lungenmetastase einer Hündin. 5 Monate nach erhaltener subkutaner Impfung des Bindegewebes einer Mammilla getötet. Impfstoff : die Produkte aus einer Kultur von Saccharomyces canis II auf Kartoffel. Oc. 4. Ob. 5. Koristka.

Figur 5. Hauptgeschwulst im grossen Netz einer Katze. Oc. 4. Ob. 5. Koristka.

Figur 6. Sarkom an der Vorhaut eines Hundes; entwickelte sich infolge subkutaner Impfung im Bindegewebe der Penisregion. Impfstoff: Prodalte aus einer Kultur von Saccharom yces canis II auf Kartoffel. Oc.4. Ob.5. Koristka.

Figur 7. Neubildungen an der Leber eines Hundes. Tod 30 Tage nach Jugularimpfung mit Parasiten und Produkten aus einer Kultur von S accharomyces canis Il. Oe. 4. Ob. 5. Koristka.

Figur 8. Metastase der Unterleibslymphdrüsen einer 38 Tage nach Abdominaleinspritzung gestorbenen Katze. Impfstoff: Produkte aus einer Kultur von Saccharomyces canis II auf Kartoffel. Oc. 4. Ob. 5. Koristka. 